\title{
Material Considerations for Fused-Filament Fabrication of Solid Dosage Forms
}

\author{
Evert Fuenmayor ${ }^{1}$, Martin Forde ${ }^{1}$, Andrew V. Healy ${ }^{1}$, Declan M. Devine ${ }^{1}{ }^{(\mathbb{D}}$, John G. Lyons ${ }^{1}$ (D), \\ Christopher McConville ${ }^{2}$ and Ian Major ${ }^{1, *}$ (iD \\ 1 Materials Research Institute, Athlone Institute of Technology, Dublin Road, N37 HD68 Athlone, Ireland; \\ e.fuenmayor@research.ait.ie (E.F.); m.forde@research.ait.ie (M.F.); andrewhealy@research.ait.ie (A.V.H.); \\ ddevine@ait.ie (D.M.D.); slyons@ait.ie (J.G.L.) \\ 2 School of Pharmacy, Institute of Clinical Sciences, College of Medical and Dental Sciences, University of \\ Birmingham, Birmingham B15 2TT, UK; c.mcconville.2@bham.ac.uk \\ * Correspondence: imajor@ait.ie; Tel.: +353-906-48-3084
}

Received: 11 March 2018; Accepted: 28 March 2018; Published: 2 April 2018

\begin{abstract}
Material choice is a fundamental consideration when it comes to designing a solid dosage form. The matrix material will ultimately determine the rate of drug release since the physical properties (solubility, viscosity, and more) of the material control both fluid ingress and disintegration of the dosage form. The bulk properties (powder flow, concentration, and more) of the material should also be considered since these properties will influence the ability of the material to be successfully manufactured. Furthermore, there is a limited number of approved materials for the production of solid dosage forms. The present study details the complications that can arise when adopting pharmaceutical grade polymers for fused-filament fabrication in the production of oral tablets. The paper also presents ways to overcome each issue. Fused-filament fabrication is a hot-melt extrusion-based 3D printing process. The paper describes the problems encountered in fused-filament fabrication with Kollidon ${ }^{\circledR}$ VA64, which is a material that has previously been utilized in direct compression and hot-melt extrusion processes. Formulation and melt-blending strategies were employed to increase the printability of the material. The paper defines for the first time the essential parameter profile required for successful 3D printing and lists several pre-screening tools that should be employed to guide future material formulation for the fused-filament fabrication of solid dosage forms.
\end{abstract}

Keywords: 3D printing; fused-filament fabrication; additive manufacturing; hot-melt extrusion; formulation; melt-blending; solid dosage forms; tablets

\section{Introduction}

Three-dimensional printing (3DP) is finding increasing utility in the manufacture of pharmaceutical dosage forms [1]. The production process is available in some different formats [2], but it can be best defined as a process that creates a physical object from a digital model through the layer-by-layer deposition of material. Potential pharmaceutical applications for 3DP are diverse and span conventional dosage forms such as tablets and implants as well as less typical pulsatory devices [3]. Spritam ${ }^{\circledR}$ is the first FDA approved 3D printed dosage form and is an orodispersible tablet containing different doses of the anti-seizure drug levetiracetam [4]. The manufacturers harness 3DP to enable high dosing $(1000 \mathrm{mg})$ while maintaining a highly porous structure that aids rapid disintegration necessary for orodispersibles. Innovation lies at the heart of the drive towards 3D printed dosage forms meant for both the creation of more complex devices and to meet the requirements of on-demand manufacturing and precision medicine [1]. 
Fused-filament fabrication (FFF) is a method of 3D printing that incorporates the hot-melt extrusion (HME) process for manufacturing a thermoplastic filament that can be fed directly to an extrusion head for melt-deposition in a pre-programmed $x-y-z$ axis. The process is also commonly known by the trademarked name Fused Deposition Modelling ${ }^{\mathrm{TM}}$. HME is a well-established process for the production of pharmaceutical dosage forms, which ensures solvent-free production, low-cost scale-up, and enhanced solubility for poorly water-soluble drugs [5]. FFF is a mainstay among 3DP amateur enthusiasts since the printers are relatively inexpensive and the filaments come in an abundance of colors. The technology is gaining interest in pharmaceutical research groups worldwide that were previously described in the production of a variety of different experimental dosage forms [6]. Producing drug-loaded filaments to strict tolerance of diameter and shape can be slow and cumbersome without the prerequisite HME processing equipment. For this reason, some groups opt to impregnate the commercial filament with the drug [7-9] while others can produce drug-loaded filaments for FFF via the HME process to print experimental tablets [7,10-19], caplets [20,21], implants [22-24], discs [25-27], and topical devices [28].

Material choice is a fundamental consideration when designing a pharmaceutical dosage form. Physical properties of the material will influence the rate of release and the type of release with the matrix polymers ranging from fully biodegradable [29] to non-degradable [30]. Material bulk properties will also deter the route of manufacturing since certain properties can exclude particular processes. A further restriction is a limited range of polymer materials with regulatory approval as excipients for the production of solid dosage forms [31]. For FFF in general, the range of materials available is very narrow compared with other conventional HME based processes. Thirty materials available commercially were compared to over three thousand for the other HME-based processes [32]. There is currently no formalized method for pre-screening materials for the FFF process [33] and there is no definitive property profile of FFF feedstock in the literature for benchmarking materials for printability. A number of pharmaceutical materials have been investigated for FFF including polyvinyl alcohol [7-9,11,12,17,20,21,27], cellulose-based polymers [13,19,24,27], polylactic acid [24,25,27,28], polycaprolactone [22,24,28], ethylene vinyl acetate [23], polyvinylpyrrolidone [15,16], Soluplus ${ }^{\circledR}[26,27]$, Kollicoat $^{\circledR}$ IR [27], and Eudragit ${ }^{\circledR}$ grades [14,18,24,26,27].

The initial concept of this work was to manufacture oral tablets by direct compression, injection molding, and FFF for comparison. Kollidon ${ }^{\circledR}$ VA64 (PVP-VA) was chosen as the polymer matrix material since it is recommended for both direct compaction and HME by the manufacturers BASF [34]. We have previously reported on the use of PVP-VA in the production of both direct-compaction [35] and injection molded [36] multi-layered vaginal tablets in which the polymer constituted the immediate release layers. However, our initial trials highlighted some issues including filament brittleness and stiffness, which prevented the simple adoption of this polymer for the FFF manufacture of similar tablets. Similar to other pharmaceutical grade polymers [26], PVP-VA has inherent limitations that prevent FFF based 3DP. These will be discussed in detail. In a wider context, the same issues will be relevant for similar pharmaceutical grade polymers without the necessary set of physical properties required for successful FFF-based 3DP. This present work aims for the first time to detail the necessary material property profile for a pharmaceutical grade polymer to successfully undergo the FFF process for complete-batch runs, which is defined as a batch that utilizes the full working surface of the print-bed without operator interference. There is a focus on the inherent compromises that must be made between printability and final dosage form properties. We outline potential difficulties faced at every stage of the FFF process and list suitable strategies to deal with each issue. We describe a melt-blending approach that can be adapted by other researchers to accommodate their specific needs from a matrix material and simultaneously overcome material shortcomings that prevent FFF 3DP. 


\section{Materials and Methods}

\subsection{Materials}

Kollidon ${ }^{\circledR}$ VA64 and Kolliphor ${ }^{\circledR}$ P188 were purchased from BASF Ireland (Cork, Ireland). Poly (ethylene oxide) (PEO) (average $\left.M_{\mathrm{WT}}=300,000\right)$ in a white powder form was obtained from Sigma-Aldrich (Arklow, Ireland). Polycaprolactone (PCL) in powder form (CAPA 6506, average $M_{\mathrm{WT}}$ $=50,000$ ) was obtained from Perstorp (Cheshire, UK). USP grade caffeine was purchased from VWR International (Dublin, Ireland). Caffeine was chosen as a Biopharmaceutical Classification System (BCS) Class I model drug since it was available in sufficient quantities to complete the overall study (of greater scope than this paper), has a melting temperature greater than the processing temperatures, and was safe for use in the environments the production equipment were located. Table 1 displays all placebo formulations manufactured in this body of work for their mechanical characterization and for pre-screening trials.

Table 1. Material formulations of melt-blends used in pre-screening.

\begin{tabular}{ccccc}
\hline Name & \multicolumn{5}{c}{ Composition by Weight (\%) } \\
\hline \multicolumn{1}{c}{ PVP-VA } & P188 & PCL & PEO \\
\hline PVP-VA & 100 & - & - & - \\
PCL & - & - & 100 & - \\
F1 & 90 & 10 & - & - \\
F2 & 90 & - & 10 & - \\
F3 & 90 & - & - & 10 \\
F4 & 80 & - & 20 & - \\
F5 & 80 & - & - & 20 \\
F6 & 70 & - & 30 & - \\
F7 & 60 & - & 40 & - \\
F8 & 50 & - & 50 & - \\
F9 & 60 & - & 30 & 10 \\
F10 & 60 & 10 & 30 & - \\
F11 & 30 & - & 60 & 10 \\
\hline
\end{tabular}

Five formulations were produced with the model drug caffeine and can be found in Table 2 . These mixtures were produced to perform drug dissolution studies to evaluate the effects of the formulations and PVP-VA loading on drug release kinetics as well as to compare tablets that were manufactured via direct compression and 3DP.

Table 2. Material formulations for drug dissolution studies.

\begin{tabular}{ccccc}
\hline Name & \multicolumn{4}{c}{ Composition by Weight (\%) } \\
\hline & PVP-VA & PCL & PEO & Caffeine \\
\hline DC 30\% PVP-VA & 30 & 55 & 10 & 5 \\
DC 60\% PVP-VA & 60 & 25 & 10 & 5 \\
3DP 30\% PVP-VA & 30 & 55 & 10 & 5 \\
3DP 40\% PVP-VA & 40 & -45 & 10 & 5 \\
3DP 60\% PVP-VA & 60 & 25 & 10 & 5 \\
\hline
\end{tabular}

\subsection{Preparation of Filaments by HME}

Thirteen material formulations are outlined in Table 1. Before HME processing, all excipients were passed through a $450 \mu \mathrm{m}$ sieve to obtain equivalent particle sizes. Each batch was mixed in a Universal Motor Drive 400 (Pharmag GmbH, Hamburg, Germany) attached to a cube mixer. The conditions for mixing all batches were kept the same at 50 RPM for $15 \mathrm{~min}$. Premixed batches were fed to an 
MP19TC25 APV Baker 16 mm co-rotating twin screw extruder (APV Baker, Newcastle-under-Lyme, UK) equipped with a purpose-built filament for Ming dye. The filament dye has a conical shaped cavity that narrows it away from the extruder, which finishes in a circular orifice (diameter $2.30 \mathrm{~mm}$ ). The gradient temperature profile of the HME process is detailed in Table 3. The screw speed was set at $80 \mathrm{RPM}$ and the feeding rate was $0.4 \mathrm{~kg} / \mathrm{h}$. The extruded batches were hauled off by using a conveyor belt system consisting of a Teflon belt that was tilted at a $45^{\circ}$ downward angle from the extruder die. A second conveyor twin-belt system was set at a sufficient haul-off speed to maintain a filament diameter of $1.75 \pm 0.10 \mathrm{~mm}$ necessary for the FFF 3D printing process.

Table 3. Temperature profile for twin-screw compounding HME (hot-melt extrusion) process to produce filament.

\begin{tabular}{cccccccc}
\hline \multicolumn{7}{c}{ Temperature $\left({ }^{\circ} \mathbf{C}\right)$} \\
\hline Zone 1 & Zone 2 & Zone 3 & Zone 4 & Zone 5 & Zone 6 & Flange & Die \\
\hline 80 & 90 & 100 & 110 & 120 & 130 & 140 & 140 \\
\hline
\end{tabular}

\subsection{Production Tablets by FFF}

FFF using F11 and formulations labelled "3DP" from Table 2 as feedstock material was carried out using a commercial desktop 3D printer, MakerBot Replicator $2 \times\left(\right.$ Makerbot ${ }^{\circledR}$ Industries, New York, NY, USA). The printing conditions for the most aesthetic and robust tablets were kept constant by using the following parameters: extrusion speed $(10 \mathrm{~mm} / \mathrm{s})$, extruder temperature $\left(150{ }^{\circ} \mathrm{C}\right)$, printing bed temperature $\left(50^{\circ} \mathrm{C}\right)$, extruder travel speed $(50 \mathrm{~mm} / \mathrm{s})$, number of shells $(1)$, roof and floor thickness $(0.5 \mathrm{~mm})$, layer height $(0.2 \mathrm{~mm})$, and infill $25 \%$ in which the linear infill pattern and the raft and support options were turned off. A total of 40 tablets were printed using these settings without any operator intervention after setup. The process was completed in $44 \mathrm{~min}$. The three-dimensional design for a flat-face plain tablet was created using SolidWorks 2014 (Dassault Systèmes, Waltham, MA, USA) and saved as an STL extension format (see Figure 1). The STL file was opened using the monitor and remote control software suite MakerBot Desktop (Makerbot ${ }^{\circledR}$ Industries, New York, NY, USA).

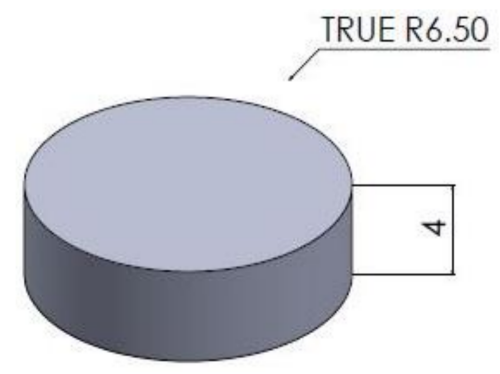

Figure 1. Three-dimensional design of a flat-face plain tablet.

\subsection{Mechanical Testing}

\subsubsection{Dynamic Mechanical Analysis}

Dynamic mechanical analysis (DMA) was performed on filaments of all formulations using TA Instruments DMA Q800 (Dublin, Ireland). The test was performed in single cantilever mode using a frequency of $1 \mathrm{~Hz}$ and an amplitude of $15 \mu \mathrm{m}$. The temperature range between $-80^{\circ} \mathrm{C}$ to $150{ }^{\circ} \mathrm{C}$ with $3{ }^{\circ} \mathrm{C} / \mathrm{min}$ rate was used to determine the storage modulus, the loss modulus, and the glass transition temperature $(\tan \delta)$ for all twelve formulations. 


\subsubsection{Filament Stiffness}

The temperature range $-80^{\circ} \mathrm{C}$ to $150{ }^{\circ} \mathrm{C}$ with $3{ }^{\circ} \mathrm{C} / \mathrm{min}$ rate was used to determine the stiffness and glass transition temperature $(\tan \delta)$ for PVP-VA, $\mathrm{PCL}$, and the eleven formulations. The test was carried with a constant frequency of $1 \mathrm{~Hz}$ and an amplitude of $15 \mu \mathrm{m}$ using the single cantilever mode. Equation (1) is the general equation of stiffness.

$$
\text { Stiffness }=\frac{\text { Load }}{\text { Deformation }}
$$

Load is defined as the force applied to the material in any given moment to obtain the desired amplitude expressed in newtons (N). Deformation is the distance the sample has moved from its original position at the beginning of the test and it is expressed in meters (m).

\subsubsection{Filament Brittleness}

The calculation of filament brittleness involved two separate tests, which were performed on $25 \mathrm{~mm}$ filament lengths of all formulations using a TA Instruments DMA Q800 (Dublin, Ireland). Storage modulus $\left(\mathrm{E}^{\prime}\right)$ values were taken in single cantilever mode at room temperature with a frequency of $1 \mathrm{~Hz}$. Cylindrical samples had a length of $17.5 \mathrm{~mm}$ and varying diameters. The test was performed in triplicate. Quasi-static 3-point bending of $25 \mathrm{~mm}$ filament lengths was performed separately on the Q800. The force applied to the samples was ramped up at $3 \mathrm{~N} /$ minute and the test was stopped when samples broke or a maximum displacement was achieved. The Brostow-Hagg Lobland-Narkis Equation (Equation (2)) for brittleness was used to obtain brittleness (B) values [37]. In the equation, $\mathrm{E}^{\prime}$ is the DMA storage modulus at $1.0 \mathrm{~Hz}$ at room temperature and strain-at-break $(\%), \varepsilon_{\mathrm{b}}$ is calculated from room temperature 3-point bending.

$$
\mathrm{B}=\frac{1}{\varepsilon_{\mathrm{b}} \cdot \mathrm{E}^{\prime}}
$$

\subsection{Melt Flow Indexing}

Melt flow indexing (MFI) was performed for all formulations in a range of temperatures. The melt flow rates (MFR) were measured using a Zwick Roell Cflow extrusion plastometer, which was equipped with a $2 \mathrm{~mm}$ orifice die. All testing was performed following the guidelines of the ASTM standard D1238-13 with a fixed weight of $2.16 \mathrm{~kg}$. Test temperatures were $140{ }^{\circ} \mathrm{C}$ and $150{ }^{\circ} \mathrm{C}$ based on the $\mathrm{HME}$ die temperature and FFF printing temperature, respectively.

\subsection{Differential Scanning Calorimetry}

Differential scanning calorimetry (DSC) was employed for thermal characterization of the virgin polymers and eleven formulations using a TA Instruments DSC 2920 Differential Scanning Calorimeter (Dublin, Ireland). Samples weighed between 8-12 mg and were placed in non-hermetical aluminum pans, which were crimped prior to testing with an empty crimped aluminum pan for reference. Each sample was summited to a heating cycle to remove thermal history consisting of a ramp from room temperature to $200{ }^{\circ} \mathrm{C}$ at a rate of $10^{\circ} \mathrm{C} / \mathrm{min}$. A cooling cycle to $0{ }^{\circ} \mathrm{C}$ was set at a rate of $5^{\circ} \mathrm{C} / \mathrm{min}$. Data recording was activated and the temperature was ramped up at a rate of $10^{\circ} \mathrm{C} / \mathrm{min}$ until it reached $200{ }^{\circ} \mathrm{C}$.

\subsection{Mass Loss Studies}

Polymer filaments with a length of $20 \mathrm{~mm}$ were tested in duplicates in dissolution media of $0.2 \mathrm{M}$ hydrochloric $(\mathrm{HCl})$ acid, $\mathrm{pH} 1.2$, and the temperature maintained at $37 \pm 0.5^{\circ} \mathrm{C}$ to mimic the stomach conditions during fasting. The stir rate was set to $60 \mathrm{RPM}$ and $25 \mathrm{~mL}$ of dissolution media was used per vial for the filament strands and $50 \mathrm{~mL}$ for the tablets. At predetermined time intervals, samples 
were withdrawn from vessels, air dried, and weighed. Samples were then placed in the oven for $12 \mathrm{~h}$ at $40^{\circ} \mathrm{C}$ and weighed again.

\subsection{Direct Compression}

Dried powder was mixed in a Universal Motor Drive (UMD) 400 (Pharmag GmbH, Klipphausen, Germany) that was attached to a cube mixer and rotated at 50 RPM for 15 min. The mixed batch was dried for a period of $12 \mathrm{~h}$ in an oven (Sanyo Gallenkamp, Loughborough, UK) at $40 \pm 0.1^{\circ} \mathrm{C}$ before being dry compressed for the manufacturing of compressed tablets. The tablet press used was a manual Atlas Series laboratory hydraulic press (Specac Limited, Orpington, UK) capable of 15 tons of pressure. The die was a hardened stainless steel evacu-able pellet die Specac GS03000 (Specac Limited) that produces tablets or disks with a diameter of $13 \mathrm{~mm}$. Tablet formulations are in Table 2. About $500 \mathrm{mg}$ of powder was accurately weighed on a Sartorius analytical balance (Sartorius, Weender Landstr, 94-10837075 Göttingen, Germany) and fed into the die. The dice and plunger were put on top of the powder and a 5-ton pressure was applied to the mixture for $30 \mathrm{~s}$.

\subsection{Drug Release Studies}

Dissolution testing of direct compressed and 3D printed tablets was performed using a Distek dissolution system 2100B with a Distek temperature control system TCS 0200B (Distek Inc., North Brunswick, NJ, USA) using to USP Dissolution Apparatus I. The tablets were tested $(n=6)$ in dissolution media $0.2 \mathrm{M}$ hydrochloric acid, $\mathrm{pH} 1.2$, and the temperature maintained at $37 \pm 0.5^{\circ} \mathrm{C}$ to mimic the stomach conditions during fasting. The stir rate was set to $50 \mathrm{RPM}$ with $900 \mathrm{~mL}$ of dissolution mediaused per vessel. At predetermined time intervals, $5 \mathrm{~mL}$ was withdrawn from each vessel and replaced with pre-heated media. The withdrawn samples were filtered through $0.45 \mu \mathrm{m}$ filter and drug release determined at $272 \mathrm{~nm}$ by performing UV spectroscopy on a Shimadzu UV-1280 UV-VIS spectrophotometer (Shimadzu, Milton Keynes, UK), which was blanked with a solution of the buffer and dissolved polymers according to the formulation tested in order to secure the detection of caffeine. The dissolution profile was observed from a plot of time versus absorbance.

\subsection{Scanning Electron Microscopy}

Scanning electron microscopy (SEM) was performed on a Mira SEM (Tescan, Oxford Instruments, Cambridge, UK) using a range of magnifications to evaluate the surface morphology of samples through the secondary electrons function. Samples were placed in a petri dish and liquid nitrogen was poured into the dish with enough to completely submerge the samples in the liquid. The lid was placed on the petri dish and left until the nitrogen totally evaporated, which was immediately followed by the transversal break of samples. Afterward, the surface of the specimens and the cross-section were examined. First, the samples were placed on an aluminum stub and were gold coated using Baltec SCD 005 sputter coater (BAL-TEC GmbH D-58579, Schalksmühle, Germany) for $110 \mathrm{~s}$ at $0.1 \mathrm{mBar}$ vacuum before observation.

\subsection{Statistical Analysis}

Data handling and analysis was performed using the Minitab 17 (Minitab Ltd., Coventry, UK). Test data was inputted into the software and, for replicate sets of data, mean and standard deviation values were calculated. The significance threshold was set at 0.05 . The mean values were presented in the figures included in the results section and error bars represent standard deviation unless otherwise specified in the figure caption. 


\section{Results}

\subsection{Mechanical Characterization}

\subsubsection{Filament Stiffness}

Filament stiffness over no minimal FFF working range of a select number of melt-blended formulations are shown in Figure 2. The nominal working range reflects the temperature range the filament experiences as feed above the driving gear (room temperature) and as a piston below the driving gear (above $30^{\circ} \mathrm{C}$ ). Addition of $10 \%(w / w)$ of the recommended plasticizer P188 (F1) decreased PVP-VA stiffness at room temperature by $69 \%$. Melt-blending with either PEO or PCL significantly decreased room temperature filament stiffness $(p<0.05)$. A 10\% $(w / w)$ addition of PEO (F3) decreased PVP-VA stiffness by just over 66\%. PVP-VA stiffness decreased by $48 \%$ in addition of $10 \%(w / w)$ PCL (F2) and continued to decrease (75\%) with double the amount of PCL (F4). Binary blends of higher amounts of PCL had no further effect on the PVP-VA room temperature filament stiffness. PVP-VA was over 200 times stiffer than PCL (306 N/m). Stiffness readings could not be made for PCL at temperatures above $56.05^{\circ} \mathrm{C}$ since the polymer had started to melt. At higher piston temperatures, PVP-VA maintained a constant stiffness up until an inflection point (onset temperature) of $68.66^{\circ} \mathrm{C}$. Above this temperature, stiffness steadily decreased with increasing temperature. While higher PCL content did not significantly affect room temperature stiffness $(p<0.05)$, the higher the PCL content, the steeper the decline in stiffness was with rising temperature. For the final formulation (F11) addition of $10 \%(w / w)$, PEO significantly decreased the stiffness across the entire working temperature range. Above $60.0^{\circ} \mathrm{C}$, there was an abrupt drop-off in filament stiffness for the final F11 formulation.

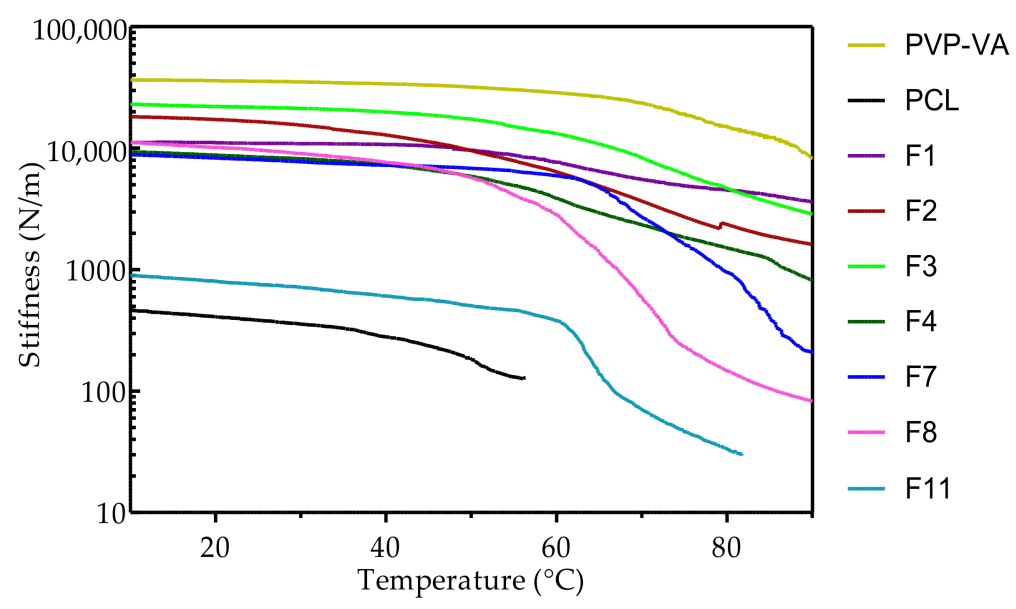

Figure 2. Stiffness $(\mathrm{N} / \mathrm{m})$ of extruded filaments within no manual working range for the FFF (fused-filament fabrication) process $\left(10^{\circ} \mathrm{C}\right.$ to $\left.90^{\circ} \mathrm{C}\right)(n=2)$.

\subsubsection{Filament Brittleness}

Table 4 shows the strain-at-break $\left(\varepsilon_{\mathrm{b}}\right)$, storage modulus $\left(\mathrm{E}^{\prime}\right)$, and brittleness $\mathrm{B} \times 10^{4}$ values obtained from filaments of the different material formulations. The B values (\%Pa) were derived from two separate mechanical tests, quasi-static 3-point bending that calculated $\varepsilon_{\mathrm{b}}$ values (\%) and a room temperature dynamic mechanical test in a single cantilever $(1 \mathrm{~Hz})$ calculated the $\mathrm{E}^{\prime}$ values $(\mathrm{Pa})$. PVP-VA showed the highest brittleness of polymers and blends with a value of $6.22 \% \mathrm{~Pa}\left(10^{4}\right)$ while PCL had a value that was $94.3 \%$ lower than that of PVP-VA at $0.35 \% \mathrm{~Pa}\left(10^{4}\right)$. The addition of $10 \%$ $(w / w)$ P188 (F1) to PVP-VA decreased its strain-at-break along with an increase in brittleness by $34 \%$. In contrast, $10 \%(w / w)$ PEO (F3) reduced the brittleness of PVP-VA by $66 \%$. Doubling the amount of PEO (F5) further decreased the brittleness by an additional 4\%. PCL decreased the overall brittleness of PVP-VA even though the effect was not as strong as that of PEO at the same concentrations. At $30 \%$ 
PCL (F6), brittleness values saw a reduction of $81 \%$. F7 is composed of $40 \%(w / w)$ PCL and the lowest value of brittleness was observed at $0.10 \% \mathrm{~Pa}\left(10^{4}\right)$. Ternary blends (F9, F10, and F11) containing P188 or PEO in addition to PCL displayed similar low brittleness values of $\sim 0.15 \% \mathrm{~Pa}\left(10^{4}\right)$.

Table 4. Brittleness (B) (\%Pa) of extruded filaments at room temperature. B values are shown as multiples of $10^{4}$ for the convenience of the reader. Storage modulus $\left(\mathrm{E}^{\prime}\right)$ was obtained at room temperature at a $1 \mathrm{~Hz}$ frequency $(n=3)$. Strain-at-break $\left(\varepsilon_{\mathrm{b}}\right)$ was obtained using a room temperature three-point bend testing $(n=5)$.

\begin{tabular}{|c|c|c|c|}
\hline Formulation & B (\%Pa) $\left(10^{4}\right)$ & $\varepsilon_{b}(\%)$ & $\mathrm{E}^{\prime}(\mathrm{Pa})$ \\
\hline PVP-VA & 6.22 & $0.85 \pm 0.19$ & $1897.89 \pm 2.27$ \\
\hline PCL & 0.35 & $59.07 \pm 1.38$ & $481.99 \pm 0.04$ \\
\hline $\mathrm{F} 1$ & 8.33 & $0.68 \pm 0.08$ & $1768.03 \pm 61.47$ \\
\hline $\mathrm{F} 2$ & 5.75 & $0.93 \pm 0.12$ & $1877.50 \pm 19.19$ \\
\hline F3 & 2.10 & $2.34 \pm 0.85$ & $2033.35 \pm 24.26$ \\
\hline F4 & 3.24 & $2.41 \pm 0.67$ & $1277.84 \pm 2.76$ \\
\hline F5 & 1.89 & $2.29 \pm 0.82$ & $2314.50 \pm 6.26$ \\
\hline F6 & 1.21 & $3.73 \pm 2.28$ & $2223.50 \pm 59.54$ \\
\hline F7 & 0.10 & $78.58 \pm 5.65$ & $1295.80 \pm 305.20$ \\
\hline F8 & 0.62 & $13.82 \pm 5.34$ & $1175.02 \pm 34.18$ \\
\hline F9 & 0.15 & $54.46 \pm 30.79$ & $1223.47 \pm 1.55$ \\
\hline F10 & 0.15 & $73.06 \pm 4.15$ & $935.16 \pm 1.08$ \\
\hline F11 & 0.14 & $72.23 \pm 6.67$ & $995.94 \pm 1.87$ \\
\hline
\end{tabular}

\subsubsection{Dynamic Mechanical Analysis}

Figure 3 displays DMA thermograms for a selected number of formulations including showing the storage modulus $\left(E^{\prime}\right)$, loss modulus $\left(E^{\prime \prime}\right)$, and tan $\delta$ across a broad temperature $\left({ }^{\circ} \mathrm{C}\right)$ sweep. The storage modulus $\left(\mathrm{E}^{\prime}\right)$ value for PVP-VA steadily decreased until the onset of a relaxation at $65.21^{\circ} \mathrm{C}$ when $\mathrm{E}^{\prime}$ value declined more steeply (see Figure 3a). PCL had a storage modulus peak at $-67.86{ }^{\circ} \mathrm{C}$ of $2479 \mathrm{MPa}$, which reflects the glass transition temperature $\left(\mathrm{T}_{\mathrm{g}}\right)$ and with increasing temperature $\mathrm{E}^{\prime}$ values steeply declined until around $-45.00{ }^{\circ} \mathrm{C}$ when the rate of decline slowed before another sharp drop prior to melting (see Figure 3b). An addition of 10\% (w/w) PCL to PVP-VA (see Figure 3c) produced a slight peak at $-56.22{ }^{\circ} \mathrm{C}$ of $2463 \mathrm{MPa}$. This lower temperature peak increased in intensity and decreased in temperature with increasing PCL content. The inflection point in the storage modulus (onset temperature) decreased in temperature with increasing PCL content up until $20 \%$ $(w / w)$ (see Figure $3 \mathrm{c}, \mathrm{d}) 62.31^{\circ} \mathrm{C}(\mathrm{F} 2)$, and $49.07^{\circ} \mathrm{C}(\mathrm{F} 4)$. At $40 \%(w / w)$ PCL, the onset temperature rose to $62.50{ }^{\circ} \mathrm{C}(\mathrm{F} 7)$ and at $50 \%(w / w)$ PCL, the onset temperature rose further to $76.70{ }^{\circ} \mathrm{C}$ (F9). For the final formulation F11, which contained 10\% $(w / w)$ PEO, displayed a much steeper storage modulus decline after $\mathrm{T}_{\mathrm{g}}\left(63.81^{\circ} \mathrm{C}\right)$ and it should be noted that $\mathrm{E}^{\prime}$ value at $\mathrm{T}_{\mathrm{g}}$ was significantly higher than for all the binary blends.

The loss modulus ( $\left.\mathrm{E}^{\prime \prime}\right)$ for PVP-VA displayed a sharp peak at $96.37^{\circ} \mathrm{C}$ (see Figure 3a) while a sharp peak for PCL was at $-59.06{ }^{\circ} \mathrm{C}$ (see Figure $3 b$ ). A secondary broad peak was apparent on the PVP-VA thermogram at $28.36{ }^{\circ} \mathrm{C}$, which may be due to the VA comonomer. Addition of $10 \%$ $(w / w)$ and $20 \%(w / w)$ PCL to PVP-VA reduced the temperature of the sharp peak to $75.98{ }^{\circ} \mathrm{C}$ and $61.31{ }^{\circ} \mathrm{C}$ and of the broad peak to $23.32{ }^{\circ} \mathrm{C}$ and $21.45^{\circ} \mathrm{C}$, respectively. For F4 (see Figure $3 \mathrm{~d}$ ), a second lower temperature broad peak appeared at $-47.41^{\circ} \mathrm{C}$. For F7, with the addition of $40 \%(w / w) \mathrm{PCL}$ (see Figure 3e), there was a significant decrease in the intensity of the sharp peak to $36.44 \mathrm{MPa}$ and an increase in the temperature to $69.19^{\circ} \mathrm{C}$. A stronger lower temperature peak appeared at $-61.91{ }^{\circ} \mathrm{C}$ and was sharper than previous low temperature broad peaks. At 50\% PCL content (see Figure 3f), the sharp peak increased in temperature to $88.50{ }^{\circ} \mathrm{C}$ and two lower temperature peaks appeared at $36.96{ }^{\circ} \mathrm{C}$ and $-69.54^{\circ} \mathrm{C}$. For the final formulation F11 (see Figure 3g), the higher temperature sharp peak was of low intensity and appeared at $64.11^{\circ} \mathrm{C}$. A distinct but rounded peak was present at $-54.59{ }^{\circ} \mathrm{C}$. 
Tan $\delta$ peaked at $126.68^{\circ} \mathrm{C}$ for PVP-VA (see Figure 3a), but it is not clearly observed for PCL due to a noisy signal starting at $55.35{ }^{\circ} \mathrm{C}$ caused by the onset of melting. For F2, the peak at $121.69{ }^{\circ} \mathrm{C}$ corresponds to that of PVP-VA (see Figure 3c). There is no peak for F4 at the higher temperatures but a shouldered peak is observed around $74.16{ }^{\circ} \mathrm{C}$ (see Figure $3 \mathrm{~d}$ ). F7 displayed a more pronounced shouldered peak at $81.09^{\circ} \mathrm{C}$ after which a crest formed at $131.97^{\circ} \mathrm{C}$ (see Figure 3e). At 50\% (w/w) PCL content, the shouldered peak was not observed but a strong, sharp peak was observed at $125.54{ }^{\circ} \mathrm{C}$ (see Figure 3f). The shouldered peak was present at $67.48^{\circ} \mathrm{C}$ in the F11 sample, but the machine could not properly measure data points at higher temperatures (see Figure $3 \mathrm{~g}$ ).

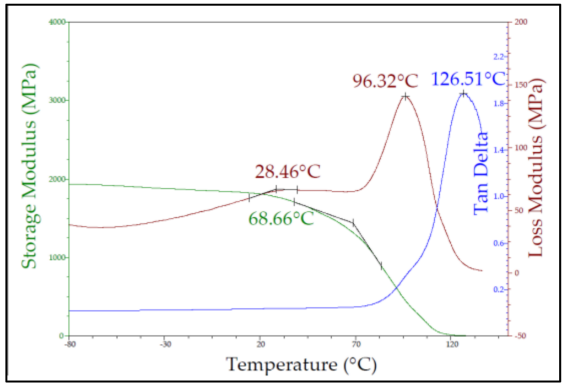

(a)

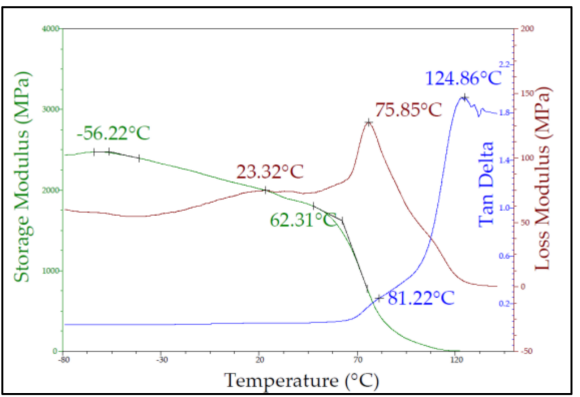

(c)

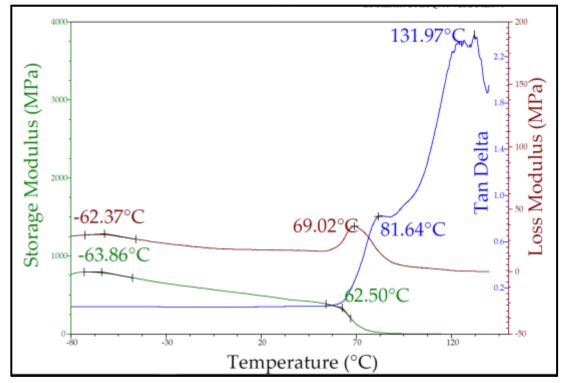

(e)

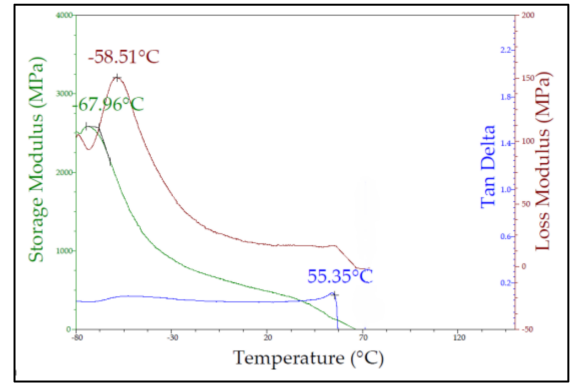

(b)

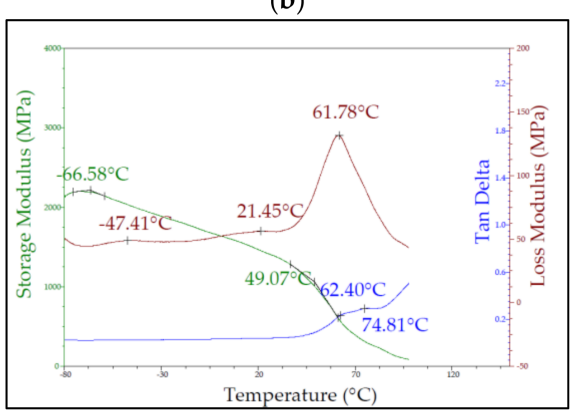

(d)

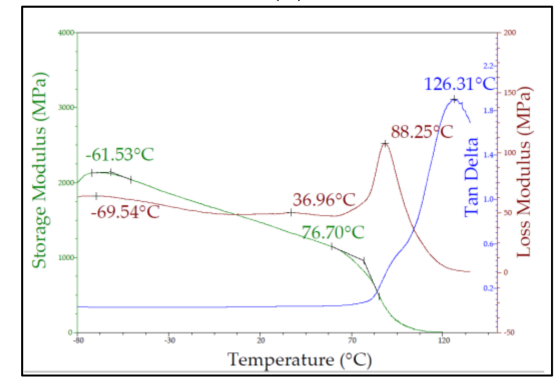

(f)

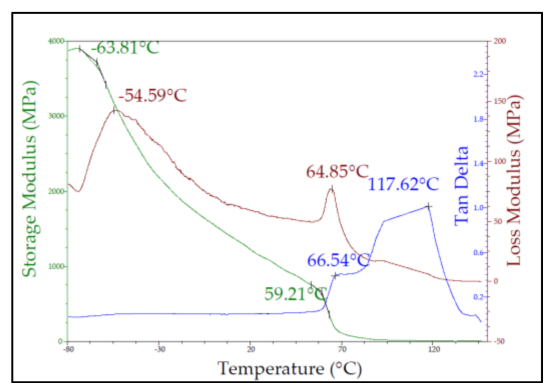

(g)

Figure 3. DMA (dynamic mechanical analysis) thermograms for a select number of formulations displaying storage modulus $\left(\mathrm{E}^{\prime}\right)$, loss modulus $\left(\mathrm{E}^{\prime \prime}\right)$, and $\tan \delta$ across a broad temperature $\left({ }^{\circ} \mathrm{C}\right)$ sweep: (a) PVP-VA; (b) PCL; (c) F2; (d) F4; (e) F7; (f) F9, and (g) F11. 


\subsection{Thermal Characterization}

Table 5 displays the thermal properties of all the base polymers and the melt-blended formulations. Extruder torque is a measure of drive motor resistance due to melt-viscosity of the polymer inside the barrel [38] and it has been proposed as a measuring tool of the relative viscosities of polymer melts during the extrusion process [39]. During these studies, the temperatures and screw speed were kept constant for all formulations. Torque readings are shown in Table 5 for the different formulations. The highest torque reading was observed for PVP-VA while PCL was the lowest. Melt-blending PVP-VA with the other polymers reduced torque. Therefore, the resistance due to viscosity was reduced. The reduction of torque recorded during the extrusion process for mixtures of polymers when compared to PVP-VA allowed for higher manufacturing throughput. However, processing conditions were kept constant to guarantee all polymers were submitted to similar stresses during manufacturing. Both PEO and P188 have a plasticizing effect on PVP-VA, but this phenomenon was better observed with formulations containing PCL. Surging, which is due to inconsistencies in the amount of material pushed out the die, was conducted typically in a sinusoidal fashion and was soothed by the incorporation of PCL. The observed surging could be due to a number of factors such as material adhering to the screw, feed entry variations in the material particle shape, or inadequate filling of the metering section of the screw. Higher concentrations of PCL further reduced the inconsistencies of the extrudate geometry. The final formulation (F11) containing $10 \%(w / w)$ PEO was observed to have reduced instances of surging compared to the binary blends.

Table 5. Extruder torque measurements, melt flow rates of polymers, and melt-blend formulations. Extruder torque measurements were recorded during twin-screw hot-melt extrusion compounding and are a measure of melt viscosity.

\begin{tabular}{cccc}
\hline Name & Extruder Torque & Melt Flow Rate at $\mathbf{1 4 0}{ }^{\circ} \mathbf{C}$ & Melt Flow Rate at $\mathbf{1 5 0}{ }^{\circ} \mathbf{C}$ \\
\hline (\%) & $\mathbf{( g / 1 0 ~} \mathbf{~ m i n})$ & $\mathbf{( g / 1 0 ~} \mathbf{m i n})$ \\
\hline PVP-VA & 40 & $0.00 \pm 0.00$ & $5.14 \pm 0.12$ \\
PCL & 10 & $11.10 \pm 0.04$ & $17.23 \pm 0.77$ \\
F1 & 15 & $4.51 \pm 0.04$ & $9.51 \pm 0.17$ \\
F2 & 20 & $3.01 \pm 0.03$ & $4.65 \pm 0.70$ \\
F3 & 15 & $2.33 \pm 0.03$ & $3.12 \pm 0.30$ \\
F4 & 20 & $2.89 \pm 0.15$ & $12.42 \pm 0.41$ \\
F5 & 15 & $0.55 \pm 0.01$ & $1.8 \pm 0.01$ \\
F6 & 15 & $4.74 \pm 0.06$ & $5.88 \pm 0.15$ \\
F7 & 10 & $6.88 \pm 0.07$ & $8.37 \pm 0.04$ \\
F8 & 10 & $3.06 \pm 0.07$ & $7.24 \pm 0.05$ \\
F9 & 10 & $9.30 \pm 0.05$ & $6.93 \pm 0.07$ \\
F10 & 10 & $7.52 \pm 0.06$ & $22.87 \pm 0.69$ \\
F11 & 10 & & $10.53 \pm 0.02$ \\
\hline
\end{tabular}

Melt flow indexing is a simple test that measures the ability of a polymer to flow when in the molten state at a given temperature. The melt flow rates for polymers and blends are shown in Table 5 for both the temperature during $\operatorname{HME}\left(140^{\circ} \mathrm{C}\right)$ and the established printing temperature $\left(150{ }^{\circ} \mathrm{C}\right)$. PVA-VA had no melt flow at $140{ }^{\circ} \mathrm{C}$ along with PEO while P188 and PCL had the higher values of all polymer and formulations, $26.4 \mathrm{~g} / 10 \mathrm{~min}$, and $11.1 \mathrm{~g} / 10 \mathrm{~min}$, respectively. There is a direct correlation between the amount of PCL incorporated into PVP-VA and increasing MFR values with melt flow increasing from batches with 10\% (w/w) PCL (F2) up to 50\% (w/w) PCL (F8) by $4.1 \mathrm{~g} / 10 \mathrm{~min}$. PEO increased the melt flow of PVP-VA to a lesser degree than PCL. However, doubling its content from $10 \%$ to $20 \%(w / w)$ had the opposite effect by decreasing MFR values from $2.3 \mathrm{~g} / 10 \mathrm{~min}$ to $1.8 \mathrm{~g} / 10 \mathrm{~min}$. F10 and F11 were found to possess the greater amount of melt flow with $9.3 \mathrm{~g} / 10 \mathrm{~min}$ and $7.52 \mathrm{~g} / 10 \mathrm{~min}$, respectively. At $150{ }^{\circ} \mathrm{C}$, PVP-VA flowed at a rate of $5.14 \mathrm{~g} / 10 \mathrm{~min}$, while PCL had an MFR of $17.23 \mathrm{~g} / 10 \mathrm{~min}$. Addition of $10 \%(w / w)$ of both P188 and PEO to the base polymer increased 
MFR of PVP-VA, with the P188 blend doubling the MFR. Addition of PCL to the PVP-VA increased the melt-flow rate. Adding 10\% and $20 \%(w / w)$ PCL had a similar effect on melt-flow while increasing content up to $50 \%(w / w)$, which was shown to double the MFR. Ternary blends had differing effects on melt-flow depending on the third polymer. Adding 10\% $(w / w)$ PEO reduced MFR and adding $10 \%$ $(w / w)$ P188 increased MFR. The final material formulation, which contained $60 \%(w / w)$ PCL and $10 \%$ $(w / w)$ PEO, had an MFR of $10.53 \mathrm{~g} / 10 \mathrm{~min}$ at $150{ }^{\circ} \mathrm{C}$.

Figure 4 shows the DSC thermograms of cooling (a) and heating (b) for PVP-VA, PCL, PEO, and the final formulation F11. PVP-VA is amorphous and thus did not generate a melting peak. The glass transition $\left(\mathrm{T}_{\mathrm{g}}\right)$ temperature of the polymer was $100.1^{\circ} \mathrm{C}$, which calculated from relaxations observed in DSC thermograms (Figure $4 \mathrm{~b})(n=4)$ and is close to the peak observed at $96.32{ }^{\circ} \mathrm{C}$ in the loss modulus (see Figure 3a). A melting peak was observed at $57.9^{\circ} \mathrm{C}$ for PCL while crystallization happened at $21.1^{\circ} \mathrm{C}$. PEO melted at $67.5^{\circ} \mathrm{C}$ and solidified at $31.1^{\circ} \mathrm{C}$. The main melting peak for F11 occurred at $57.0^{\circ} \mathrm{C}$ with a small shoulder at $62.2^{\circ} \mathrm{C}$. The main peak would represent the PCL portion of the ternary blend while the shoulder would represent the $10 \%(w / w)$ PEO portion. From the cooling cycles, two solidification peaks are observed at $30.4{ }^{\circ} \mathrm{C}$ and $43.2^{\circ} \mathrm{C}$, which would again represent PCL and PEO, respectively. A $5 \%(w / w)$ caffeine loading to $\mathrm{F} 11$ did not produce a melting peak at $235^{\circ} \mathrm{C}$ to $237^{\circ} \mathrm{C}$ and it did not alter the MFI values of the formulation. Therefore, further characterization is beyond the scope of this body of work (data not shown).

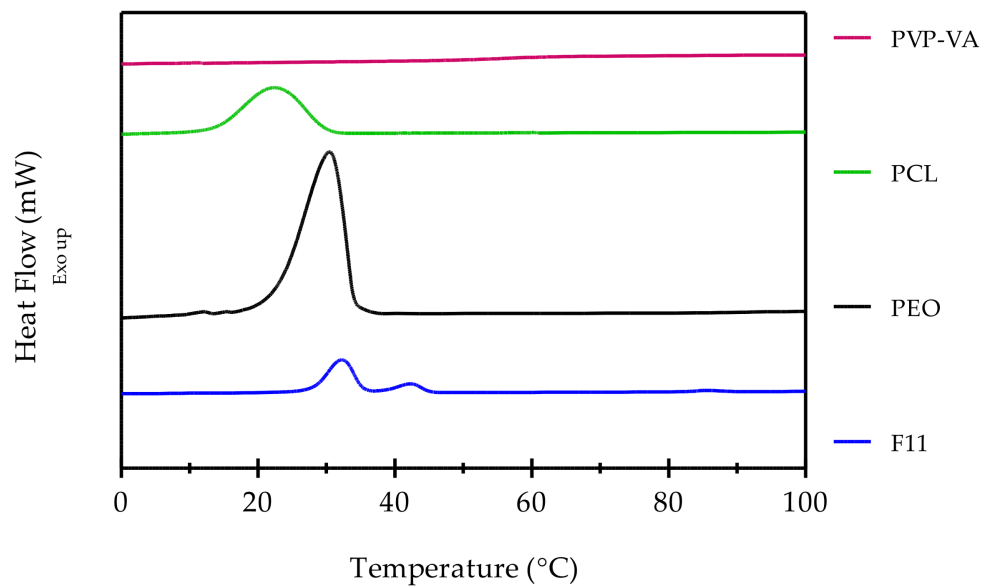

(a)

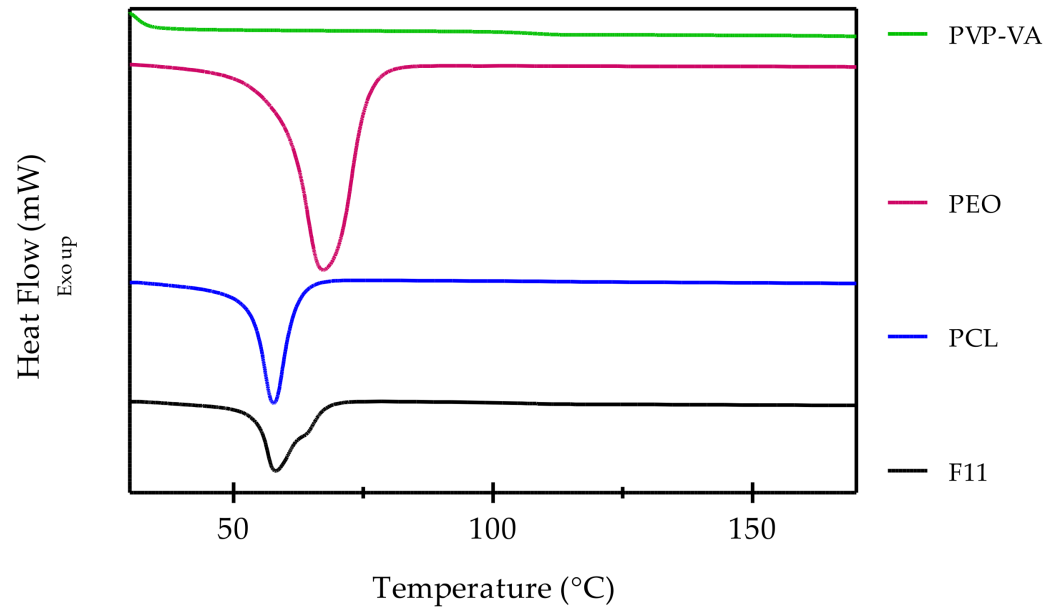

(b)

Figure 4. Overlaid DSC (differential scanning calorimetry) thermograms of the three base polymers and the F11 melt-blended formulation: (a) cooling and (b) heating. 


\subsection{Dissolution Studies}

\subsubsection{Mass Loss}

The mass loss of select blends was measured over a period of $8 \mathrm{~h}$ to ascertain the effect of changes in material formulation on the disintegration profile of PVP-VA. Figure 5 shows the remaining mass (\%) over time of a formulation filament in biologically relevant media. PVP-VA was shown to completely disintegrate within the first two hours, which would be expected for a polymer designed for immediate release applications. Adding PCL to the formulation slowed the rate of mass loss. Adding $10 \%(w / w)$ PCL reduced mass loss to $42.4 \%$ in the first $2 \mathrm{~h}$ by increasing to $82.8 \%$ at $4 \mathrm{~h}$ and only a tiny $3.1 \%$ portion remained after $8 \mathrm{~h}$. Doubling the amount of PCL to $20 \%$ slowed mass loss even further, and after $4 \mathrm{~h}$, more than twice the amount of mass remained ( $45.7 \%$ ) compared to the $10 \%$ PCL sample. After $8 \mathrm{~h}$, more than a fifth of the mass remained (21.7\%) for this formulation. At higher PCL loadings, the linear pattern stopped. The sample containing $40 \%$ PCL is of particular note since it lost $44.8 \%$ mass after $4 \mathrm{~h}$ but regained $11.8 \%$ after $6 \mathrm{~h}$. The formulations with a content of $50 \%(w / w)$ PCL and more displayed a slower rate of dissolution in media with more than $75 \%$ of their mass still intact after an 8 hour-period.

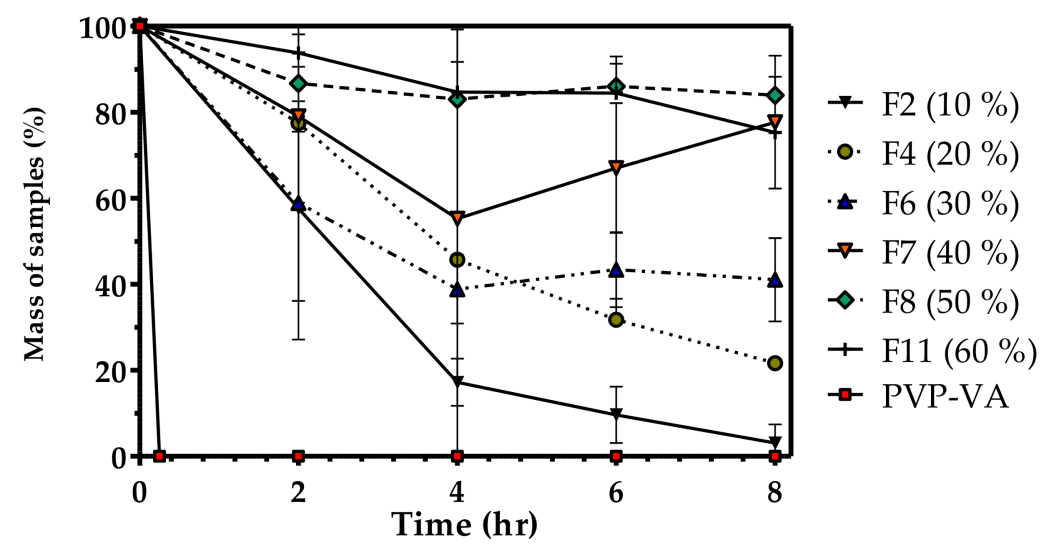

Figure 5. Percentage of mass loss in $\mathrm{HCl}$ media, $\mathrm{pH} 1.2,0.2 \mathrm{M}$ at different time points. Percentage values in legend correspond to PCL (polycaprolactone) content $(w / w \%)$.

\subsubsection{Cumulative Drug Release}

The influence of material formulation and tablet manufacturing processes on drug release over 48 $\mathrm{h}$ is shown in Figure 6. Two compressed tablets of different formulations ( $30 \%$ and $60 \%(w / w)$ PVP-VA content) both released over $75 \%$ drug content after $6 \mathrm{~h}$. Similarly, a 3D printed tablet containing 30\% $(w / w)$ PVP-VA released $78.3 \%$ drug after $6 \mathrm{~h}$. There was no significant difference in the release profiles of these three tablets $(p<0.05)$. The presence of PCL in the formulation slows caffeine drug release and the immediate release properties of PVP-VA. A PVP-VA compressed tablet released $100 \%$ drug in under $1 \mathrm{~h}$ (data not shown). For a 40\% ( $w / w)$ PVP-VA 3D printed tablet, the cumulative release was not significantly different for time points up to $6 \mathrm{~h}$. Beyond this point, the cumulative release from the tablet slowed significantly compared to other tablets. After $8 \mathrm{~h}$ and $24 \mathrm{~h}$, the tablet had released $83.8 \%$ and $97.3 \%$ drug, respectively. There was a significant difference in the release profile of the $30 \%(w / w)$ PVP-VA 3D printed tablet and the other tablets at almost all time points. After $6 \mathrm{~h}$, this tablet released $38.5 \%$ of the drug with $50.1 \%$ release of the $30 \%(w / w)$ PVP-VA 3D printed tablet. After $24-h$ release increased to $80.1 \%$ and, after $48 \mathrm{~h}$, the release was $92.3 \%$. 


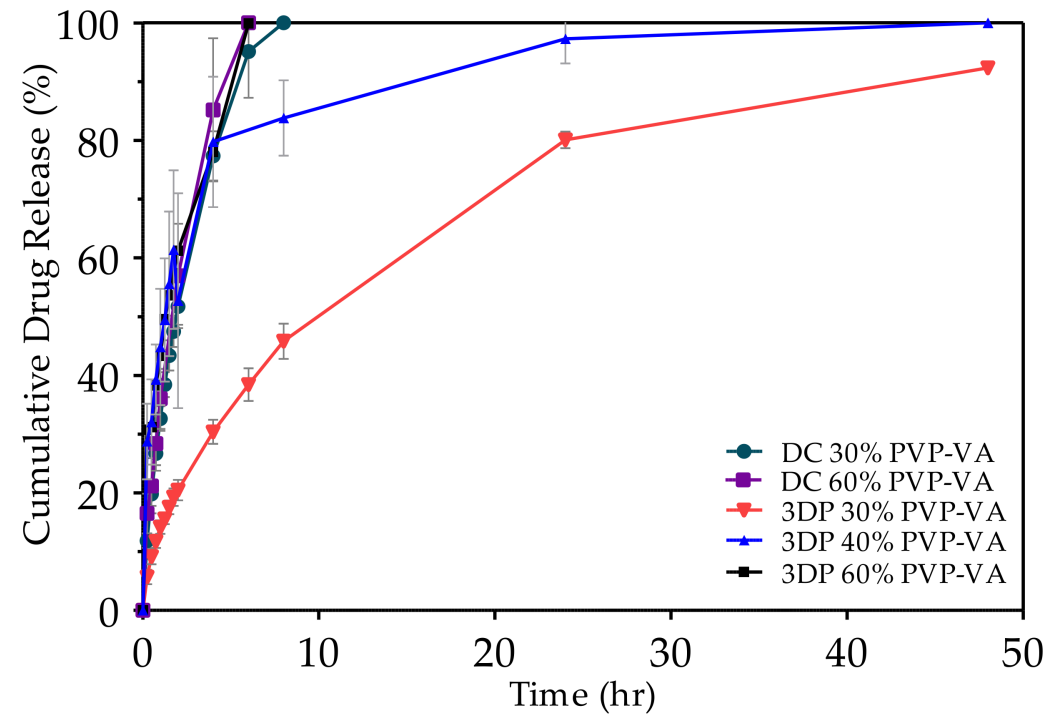

Figure 6. Cumulative caffeine release over $48 \mathrm{~h}$ in $\mathrm{HCl} 1.2 \mathrm{pH}, 0.2 \mathrm{M}$ media for different tablet formulations produced via direct compression. Percentage of PVP-VA (polyvinylpyrrolidone-vinyl acetate) reflects material composition only, which contains $10 \% w / w$ PEO (polyethylene oxide) with the remainder being composed of PCL. All formulations contain $5 \% w / w$ caffeine in the overall composition.

\section{Discussion}

\subsection{Material Formulation Rationale}

PVP-VA is a copolymer of polyvinylpyrrolidone (PVP) and vinyl acetate (VA). The addition of the VA side chains increases the hydrophobicity of PVP. The polymer has previously been used in the production of amorphous solid dispersions [40-44], as a release modifier [45], and has been blended with PCL for the production of tissue engineering scaffolds [46,47]. Our initial HME trials to produce PVP-VA filaments for FFF were unsuccessful. The material proved to be brittle and the filament would snap during the HME downstream haul-off process. Therefore, our approach was to modify PVP-VA sufficiently through melt-blending so that it would form a suitable filament. We aimed to find a material formulation incorporating PVP-VA, which would permit the production of a complete batch $(n=40)$ of flat-face plain tablets during a single print run. Kolliphor ${ }^{\circledR}$ P188 is the recommended plasticizer by the supplier BASF ${ }^{\circledR}$ [34]. In addition to the plasticizer, there were no observable changes in the flexibility of the filament. Very high loadings of P188 produced extrudate that would crumb and not form consistent filaments. Therefore, other polymers were investigated to blend with PVP-VA.

Blending during the HME process is a means of combining properties of different polymers into a single final object [48]. Melt-blending is not a new concept in drug delivery as with industrial applications. It is a means that provides the final dosage form with refined or a broader set of properties. We have previously reported on blending polyethylene vinyl acetate (PEVA) with polylactic acid (PLA) to improve the release of hydrophilic tenofovir from PEVA intravaginal rings [49]. The production of solid dispersions has benefited greatly from melt-blending. Polyethylene glycol (PEG) is by far the most widely used polymer in the production of solid dispersions due to low melting points, fast solidification behavior, and low toxicity [50]. However, such formulations made from the polymer are unstable. Some authors have described the positive impact of melt blending [40,50,51]. Bley et al. [40] describe the production of solid dispersions of PEG and different polymers via co-melting. The addition of polymers was aimed at stabilizing amorphous forms of water-insoluble drugs in PEG-based solid dispersions. The researchers found that blends of PEG with PVP-VA were less viscous than the pure polymers and that the PEG/PVP-VA blend created the best solid dispersion regarding both the 
dissolution rate and amorphous drug stability for both drugs. Therefore, melt-blending and careful polymer selection provided an advantage compared to using a single polymer.

Melt-blending for FFF has been described a number of times in prior studies. Rocha et al. [52] described the production filaments from acrylonitrile butadiene styrene (ABS) based binary and ternary polymer blends. The printed parts produced from the blends displayed different mechanical, physical, and surface properties compared to the neat ABS samples. Printability could be maintained across a broad range of compositions and miscibilities. Roberson et al. [53] described the utilization of melt-blending to develop materials for specific applications and how it can be used to overcome specific shortcomings inherent to printing with the neat polymers. The same group described melt-blending ABS with thermoplastic elastomer styrene ethylene butylene styrene (SEBS) grafted with maleic anhydride to produce a flexible material suitable for the production of actuators [54]. Through melt-blending, the authors were able to produce prints with comparable performance to those using higher cost polyurethane filaments. Although the majority of other studies are concerned with non-pharmaceutical polymers [55-57], some researchers are examining melt-blends in FFF for medical applications. Kosorn et al. [58] produced blends containing different compositions of polycaprolactone (PCL) and poly(3-hydroxybutyrate-co-3-hydroxyvalerate) (PHBHV) for porous scaffolds. Higher PHBHV content improved compressive strength, increased chondrocyte proliferative capacity, and enhanced chondrogenic potential. Alhijjaj et al. [26] used melt-blending to improve printability and control drug release from printed solid dispersions. The researchers created Eudragit EPO or Soluplus based blends with PEG, PEO, and Tween 80 and achieved excellent printability and drug dispersion. Blend composition had a significant influence over disintegration behavior and rates of drug release.

Since PVP-VA proved to be unprintable due to brittleness and high stiffness, our strategy was to melt-blend PVP-VA with another polymer that had the inherent flexibility and ductility. Ideally, the polymer would also be well-established for FFF 3DP, drug delivery, and be biocompatible. One polymer that fits the criteria is PCL. The polymer has a long history in the FFF 3DP and one of the earliest research articles on FFF for biomedical applications described the use of PCL in the production of a scaffold [59]. PCL-based drug delivery systems present high drug permeability, excellent compatibility with many drugs, and full excretion from the body once absorbed, which makes the polymer an excellent choice [60]. A possible disadvantage of PCL is the slow degradation rate that would likely impede the immediate release properties of PVP-VA, but this was not a hindrance for us since our main consideration was to use a material that could be utilized in HME, direct compaction, and injection molding. For the interested reader, a recent paper by Solanki et al. [61] describes a formulation strategy for FFF that maintains the immediate release properties of PVP-VA through melt-blending with hydroxypropyl methylcellulose and hydroxypropyl methylcellulose acetate succinate. PEO was also included in the current formulation trials since we wished to reduce the hydrophobicity of the PCL [62]. We have previously had success blending PCL with PEO to form an oral tablet [38] and such blends have been reported elsewhere as efficient drug carriers [63-65].

\subsection{Filament Production}

For our purposes, we wished to melt-blend polymers with drug and create filament in a single step. To do this requires the use of a twin-screw extruder that provides for better mixing of the drug within a polymer compared to a single screw extruder [30]. Figure 7a,b show our filament extrusion setup and Figure 7c is the design of the die attachment that was attached to the front-face of the twin-screw extruder. The conical design for the attachment allows for an increase in die pressure without applying excessive shear force on the polymer melt since excessive shear can degrade certain polymers [66]. The design also permits for a steady flow of material out of the extruder. The consistency is a key feature needed for the manufacture of FFF filament strands since the margin of tolerance for the dimensions of the extrudates is narrow. The strands needed to have a diameter of $1.75 \mathrm{~mm} \pm 0.10 \mathrm{~mm}$ to pass through the driving gear and into the liquefier. Any values below or above this range are not feasible as a feedstock material for the MakerBot ${ }^{\circledR} 3 \mathrm{D}$ printer. 


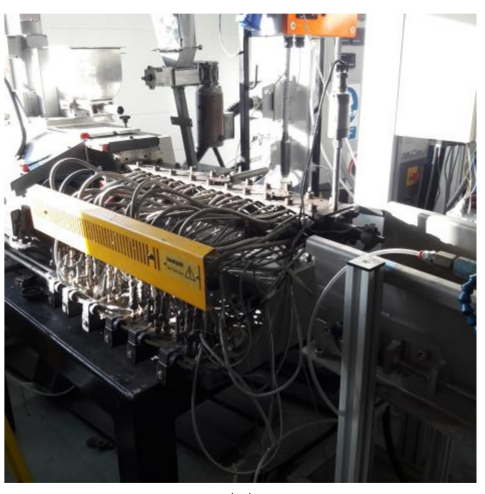

(a)

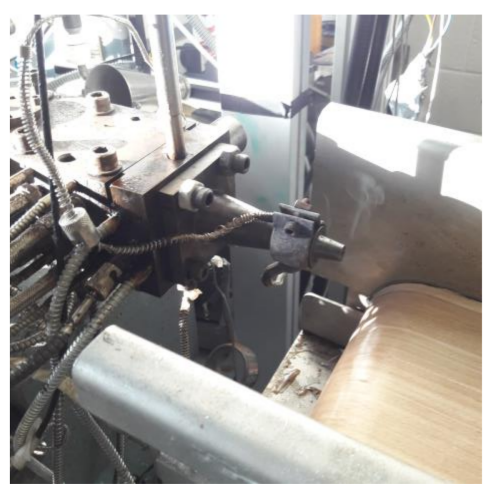

(b)

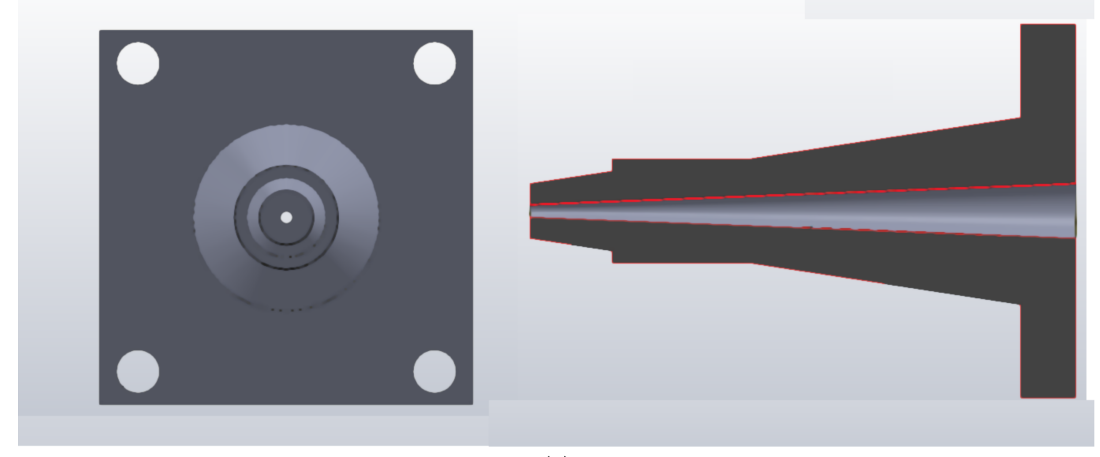

(c)

Figure 7. Depiction of machinery used for the fabrication of formulations described in this body of work: (a) twin-screw extruder, (b) mounted die attachment on extruder flange, and (c) schematic of die attachment.

The front orifice of the die attachment was designed with a diameter of $2.30 \mathrm{~mm}$, which allowed the extruded filament to be larger than needed so that control of the filament diameter was completed through subsequent unidirectional stretching by the haul-off units. Since we did not have access to a melt-pump system, compensation for extrusion surging was through operator control of the haul-off speed. The extrudate filament was cooled through a system of air knives and not through a water-bath to prevent erosion of the water-soluble polymer filament and drug loss. The haul-off system was in two stages: a first Teflon belt at a $45^{\circ}$ decline with air knife cooling and a second twin belt conveyor that was the dominant haul-off controller. Figure 8 shows the physical appearance of a select number of filaments produced during HME trials. The majority of formulations gave filaments with a rough surface, which is indicative of the onset of sharkskin. The sharkskin appearance is indicative of instabilities in the flow exiting the die [67] and is probably related to the immiscible portions of the melting portion. Higher die temperatures may have resolved the issue. Both polymers, PVP-VA and PCL, and F6 all produced filaments with a smooth surface with no sign of sharkskin, which suggested stable melts at these processing temperatures [67]. For the most part, the die attachment reduced surging from the twin-screw extruder, but some operator intervention was still required to maintain tolerances. Addition of $10 \%(w / w)$ PEO had the unexpected benefit of almost eliminating extrusion surging in the final $60 \%(w / w)$ PCL formulation. 
PCL

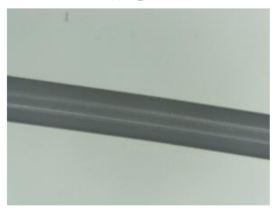

F8

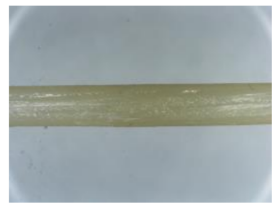

PVP-VA

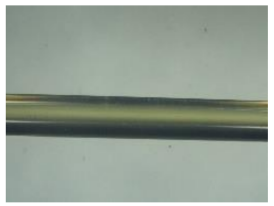

F9

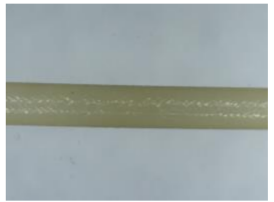

F5

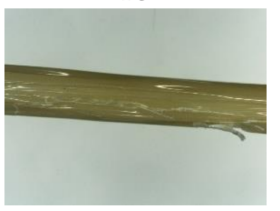

F10

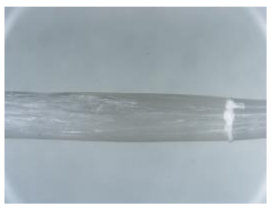

F6

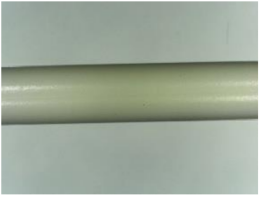

F11

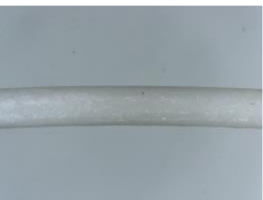

Figure 8. Physical appearance of filaments from select formulations made via hot-melt extrusion.

\subsection{Filament Characterization}

For PVP-VA printability to improve, it had to be modified to remove brittleness and decrease stiffness. Figure 2 shows stiffness of the filaments for a select number of formulations. On melt-blending, with the other polymers, the stiffness was reduced sufficiently to permit coiling. We estimate from our data that filament stiffness should not exceed $1000 \mathrm{~N} / \mathrm{m}$ to enable consistent coiling. In addition, from our experience, as stiffness surpasses 10,000 N/m, the printable length of filament shortens. Filaments must also be able to resist buckling after the driving gear due to the force applied during feeding since the filament acts as a piston on the molten polymer in the liquefier [33,68]. Venkataraman et al. [68] derived a relationship of elastic modulus (in compression) to apparent viscosity in which a critical ratio $\left(3.00-5.00 \times 10^{5} \mathrm{~s}^{-1}\right)$ ensures a material will not buckle during FFF, i.e., the filament is sufficiently stiff to act as a piston and drive out molten polymer in the liquefier through the nozzle. Insufficient stiffness was not an issue for PVP-VA and the reverse was more of a concern since the filament could not be coiled for proper feeding. The column strength critical ratio to prevent buckling can be assumed to have been maintained since buckling was not observed. We were unable to directly calculate the ratio without access to a capillary rheometer.

The second main issue with PVP-VA was the inherent brittleness that created issues during filament production and feeding of the FFF extrusion head. To quantify brittleness, the Brostow-Hagg Lobland-Narkis equation for Brittleness (B) (Equation (2)) was used [37]. Strain-at-break $\left(\varepsilon_{\mathbf{b}}\right)$ is a measure of a material's ductility and is usually recorded during tensile testing as elongation-at-break $(\%)$. Storage modulus $\left(E^{\prime}\right)$ is the solid-like (elastic) response to stress and is usually recorded during dynamic mechanical analysis (DMA). The authors specify the DMA conditions at room temperature for a frequency of $1 \mathrm{~Hz}$. The elegance of this equation is that it requires results from two forms of mechanical testing-quasi-static and dynamic. For convenience, we took results directly from extruded filaments and not tensile specimens. Therefore, we derived brittleness (B) from strain-at-break $\left(\varepsilon_{b}\right)$ values obtained from 3-point bend testing by using deflection rather than elongation values. The true value of this approach derives from direct testing of filaments with comparable stress (flexural) applied to filament passing through the driving gear system. The equation should enable researchers to prescreen material formulations for suitability. Since the driving gear mechanisms of different FFF printers will vary, researchers can determine the critical brittleness $\left(B_{c}\right)$ for their system, above which it will be known that the filament will fail. The results in Table 4 aided us in quantifying observations about filaments that had failed to print since the filaments that had failed to negotiate the Makerbot ${ }^{\circledR}$ system had B values higher than $2.00 \% \mathrm{~Pa}\left(10^{4}\right)$. Thus, $\mathrm{B}<0.0002 \% \mathrm{~Pa}$ will be a critical material characteristic for future material formulations for this printer.

Figure 9 shows the finished print of a complete batch of tablets. Part of the pre-screening process is to calculate the length of filament required to print a complete batch of $13 \mathrm{~mm}$ diameter tablets. Most printer software will pause a print mid-run to permit changing of the filament and, therefore, it is not an insurmountable issue, but from a purely practical point-of-view, it is important to be aware of 
how large of a batch can be printed from a single filament length. Equation (3) was used to calculate the density $\left(D_{b}\right)$ of the ternary blend F11 $\left(0.001141 \mathrm{~g} / \mathrm{mm}^{3}\right)$. The total volume $\left(V_{T}\right)$ of forty $4 \mathrm{~mm}$ high (cylinder) tablets was $21,237.16 \mathrm{~mm}^{3}$ (Equation (4)) where $\mathrm{h}_{\mathrm{T}_{\mathrm{s}}}$ is the total height of sample tablets combined and $\mathrm{r}_{\mathrm{s}}$ is the radius of the tablet. The total mass $\left(\mathrm{M}_{\mathrm{T}}\right)$ to print forty $100 \%$ infill tablets was calculated at $24.23 \mathrm{~g}$ (Equation (5)). Finally, the length of required $1.75 \mathrm{~mm}$ diameter filament to print forty $100 \%$ infill tablets could be calculated as $8829.32 \mathrm{~mm}$ using Equation (6) where $\mathrm{r}_{\mathrm{f}}$ is the radius of the filament. We refer to this as the minimum batch length $\left(\mathrm{L}_{\mathrm{B}}\right)$. The filament length should be adjusted for the percentage infill (x) of samples, e.g., 0.25 for a $25 \%$ infill, which reduces the length to $2207.33 \mathrm{~mm}$. In addition, to account for variation in filament diameter and the material needed for the outer shell, a correction factor of at least 1.3 should be applied, which would bring the minimum batch length $\left(L_{B}\right)$ for these tablets to $2869.53 \mathrm{~mm}$. In further criteria, we set any material formulation is the minimum sample length $\left(\mathrm{L}_{S}\right)$, which is the minimum filament length to print a single sample without operator intervention. The $\mathrm{L}_{\mathrm{S}}$ for this design of flat-face tablet with $25 \%$ infill is $71.74 \mathrm{~mm}$. We consider $\mathrm{L}_{S}$ to be the minium criteria of viability for any material formulation for the FFF process. PVP-VA could not pass this minimum criteria $\left(\mathrm{L}_{S}\right)$ due to brittleness. F5 was the first formulation to pass this criteria, but only F11 could succeed in passing the minium batch length $\left(\mathrm{L}_{\mathrm{B}}\right)$ and provide a filament in excess of $8.83 \mathrm{~m}$. To achieve the $\mathrm{L}_{B}$ required for the quite high PCL content, it ultimately reduced the drug release rate (see Figure 6). Therefore, printability versus the drug release profile is a choice that can guide future formulation. We can maintain more of the immediate release properties of PVP-VA by reducing PCL content but at the cost of the filament length and subsequent batch size. $\mathrm{L}_{\mathrm{S}}$ is the limit at which PCL content can be reduced.

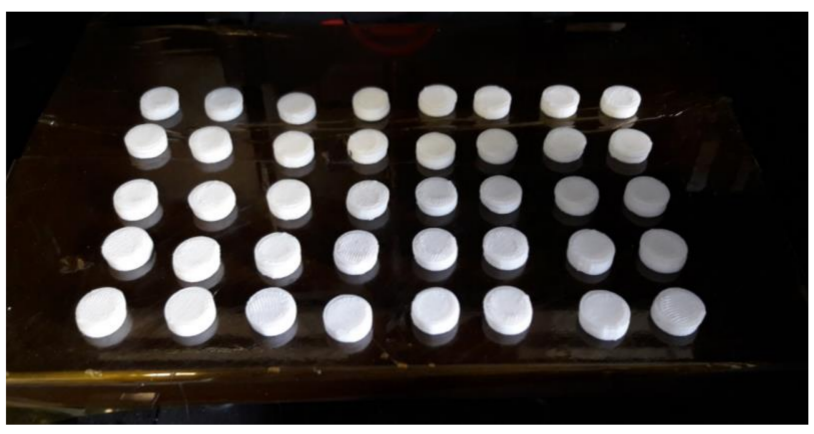

Figure 9. Complete batch of flat-faced tablets produced via FFF 3D printing. Total of 40 tablets covered the print bed of MakerBot Replicator 2X.

$$
\begin{gathered}
\mathrm{D}_{\mathrm{b}}=\mathrm{x}_{1} \mathrm{D}_{1}+\mathrm{x}_{2} \mathrm{D}_{2}+\mathrm{x}_{3} \mathrm{D}_{3} \\
\mathrm{~V}_{\mathrm{T}}=\pi \mathrm{h}_{\mathrm{T}_{\mathrm{s}}} \mathrm{r}_{\mathrm{s}}^{2} \\
\mathrm{M}_{\mathrm{T}}=\mathrm{D}_{\mathrm{b}} \mathrm{V}_{\mathrm{T}} \\
\mathrm{L}_{\mathrm{B}}=\frac{\mathrm{h}_{\mathrm{T}_{\mathrm{s}}} \mathrm{r}_{\mathrm{s}}^{2}}{\mathrm{r}_{\mathrm{f}}^{2}}
\end{gathered}
$$

\subsection{D Printing of Flat-Faced Tablets}

Formulation F11 was chosen for the material blend's ability to overcome the physical restrictions of the FFF process and to form a consistent filament to be fed to an extrusion head. Filament is usually spooled at the point of production on the downstream equipment. Spooling is usually the most convenient approach with spools sold in $\sim 1 \mathrm{~kg}$ batches. However, it is possible to create successful prints with unspooled filaments if it is unobstructed and can move freely. Figure 9 shows the finished print of a complete batch of tablets. Forty $13 \mathrm{~mm}$ diameter tablets is the maximum number that could be consistently printed on the print bed of the Makerbot ${ }^{\circledR}$ system. The print-bed is covered with a 
disposable high-temperature Kapton ${ }^{\circledR}$ polyimide tape, which glues the first layer deposited. No raft or support structures are required for flat-face tablets. The outer wall of tablets was made by one solid shell. The roof and floor were also solid and had a depth of $0.5 \mathrm{~mm}$. Infill density was set to $25 \%$ and the infill pattern was linear. These settings create a tablet with a shell structure with $75 \%$ of its inner volume consisting of void space.

Figure 10 shows examples of the main types of part failure during the FFF process. Stringing (see Figure 10a) occurs when excess material on the nozzle is dragged from the part during manufacturing. The problem is more pronounced for materials with a high melt strength that will readily allow for stretching of molten beads. Some printing software has a 'retraction' countermeasure setting that eases back pressure in the extrusion head to prevent oozing from the nozzle during print head travel. Other reasons that could cause this flaw are two high nozzle temperatures that cause low material viscosity over extrusion of material and slow cooling of deposited material due to high print bed temperatures. Layer splitting (see Figure 10b) occurs due to inadequate layer coalescence during deposition. The polymer chains in the depositing molten layer must intermingle with the polymer chain of the previous layer to achieve proper coalescence. If adequate coalescence is not achieved, then during cooling, elimination will occur and layers will split apart. Higher printing and print-bed temperatures will overcome this issue since lower viscosities and softening of printed layers will both promote coalescence. Warping (see Figure 10c) is a phenomenon that is not restricted to FFF but occurs in other processes including injection molding [69]. In the FFF process, it occurs due to poor adhesion of the base layer to the print-bed and when subsequent layers are deposited on top. Internal stress between the layers of the print causes the part to warp and curl away from the print-bed surface. One of the main reasons for warping is the too low print-bed temperature that creates an excessive thermal gradient [70].

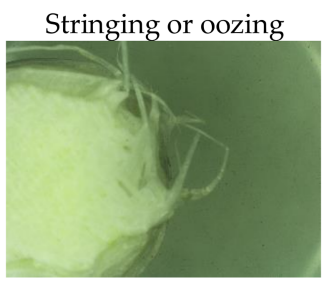

(a)

Weak infill

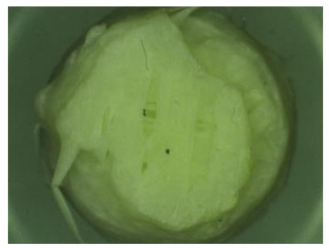

(d)

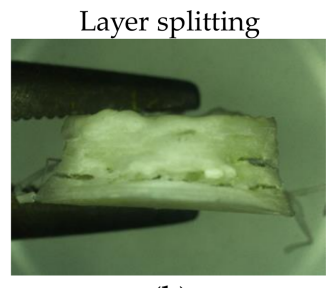

(b)

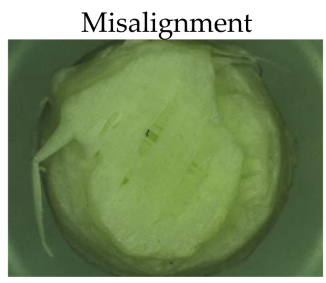

(e)

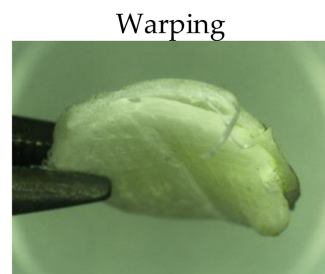

(c)

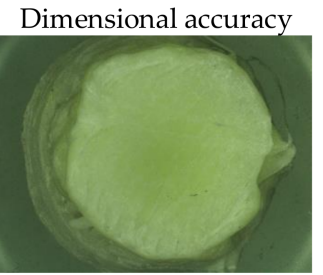

(f)

Figure 10. Most common print deformities that occur during the FFF 3D printing.

Infill determines the amount of material printed between the outer shells of a 3DP part. A weak infill (see Figure 10d) will fail to provide inner support to the part, which compromises the final mechanical integrity. Weak infill can be caused by choosing the wrong infill pattern for the specific inner geometry of the part. Too high a printing speed that prevents consistent layer deposition and poor layer deposition as a result of inconsistent feeding due to problems with the feedstock or melt-feed. Misalignment (Figure 10e) is due to discrepancies in the printers and the $\mathrm{x}-\mathrm{y}-\mathrm{z}$ axis dimensions. Most FFF printers have an open loop system without feedback sensors, which means that the printer will print the preprogrammed CAD design regardless of any misprint in the previously deposited layers. Assuming the print-bed is properly calibrated, the operator must manually adjust program settings based on the performance of the material to ensure that the settings (print speed, 
layer height, layer thickness, and more) are achievable. Other reasons for misalignment are related to hardware issues such as deficiencies in the stepper motor or tension belts. Relatedly, dimensional accuracy (see Figure 10f) is caused by extrusion problems, print-bed calibration accuracy, and filament quality. Any fluctuation in the material being deposited will disrupt the dimensions of the part while a nozzle that is closer or further than intended from the printing bed will have a similar consequence to the former.

\subsection{Tablet Properties}

Mass loss and drug release studies were used to assess the effect of changing material formulation for dissolution. As would be expected, adding a hydrophobic PCL to the PVP-VA had a significant retardation effect on the mass loss rate (see Figure 5). The PCL content significantly reduced the drug release rate (see Figure 6) while PVP-VA fully released drugs within the first hour. The $60 \%(w / w)$ PCL took over $8 \mathrm{~h}$ to complete. For us, the immediate drug release properties of PVP-VA was not a critical factor for our tablets and was chosen for the suitability for both direct compression and HME tablet production processes. If immediate drug release had been a critical factor, then our material formulation could easily have been changed to suit this criterion. For example, the PEO content could have increased or we could have chosen a water-soluble polymer such as polyvinyl alcohol instead of PCL. Melt-blending has the inherent flexibility to change formulation at will to meet such needs. The different nature of the manufacturing processes influenced the release rate of the drug substance of tablets with the same formulations (see Figure 6). The HME process intimately mixes polymer chains in the molten state and they remain entangled when solidified. DC tablets contain the polymers as powdered mixtures that form strong interparticulate bonds during compression, but the polymer chains are not entangled. In addition, the DC tablet containing $60 \%(w / w)$ PCL completely disintegrated after $8 \mathrm{~h}$, which enabled the total release of the drug.

The DMA thermograms show that the binary blends of PVP-VA and PCL are only partially miscible. Complete miscibility of binary blends usually coincides with the formation of a single $T_{g}$ peak [71]. Tan $\delta$ peaks for the binary blends show that increasing PCL content produced two distinct $\mathrm{T}_{\mathrm{g}}$ peaks, but these peaks moved closer together as PCL content increased. This is characteristic of partial miscibility [72]. The absence of two distinct Tan $\delta$ peaks with increasing PCL up to $20 \%$ $(w / w)$ PCL and the appearance of two distinct peaks at higher loadings would suggest that PCL is miscible in PVP-VA up to 20\% $(w / w)$ content. Mass loss and drug dissolution data both suggest that when the PCL exceeds $20 \%(w / w)$ of the composition, the PVP-VA becomes entrapped with the PCL matrix as domains. Figure 11 shows SEM scans of the polymers and formulation F11 (containing 5\% $(w / w)$ caffeine). The increase in mass after $4 \mathrm{~h}$ during the mass loss study for the F6 and F7 blends could be due to the swelling of the PVP-VA domains encapsulated by the PCL matrix from ingress of media. SEM of the printed F11 tablet was inconclusive with regard to miscibility, other than showing that the morphology of the ternary blend was highly disordered. The open structure of $25 \%$ infill tablets is very clear. Monoclinic caffeine is clearly distinguishable and a white spongy layer is also visible. Since PVP-VA is glassy, it is more likely that this spongy layer is a PEO domain. The presence of PVP-VA is not readily discernible. Since miscibility was unimportant to us, it was not studied beyond the scope of the data presented and would warrant much deeper investigation to pick apart the miscibilities present within the ternary blend. Miscibility is only a criterion for FFF of solid dosage forms if immiscibility is detrimental to the performance of the filament or significantly impairs the performance of the final dosage form. In this study, as with others [52], any blend immiscibility did not impede the printing of parts. 


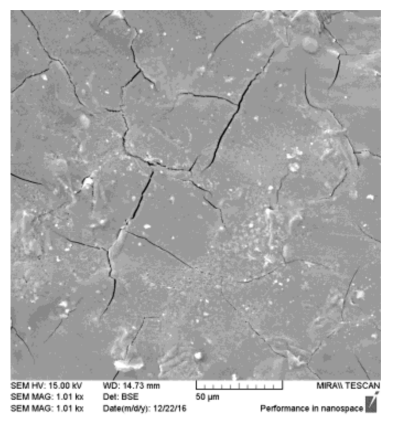

(a)

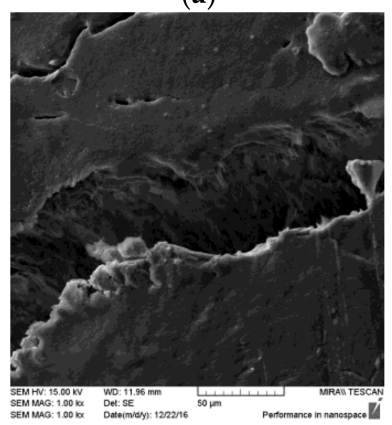

(c)

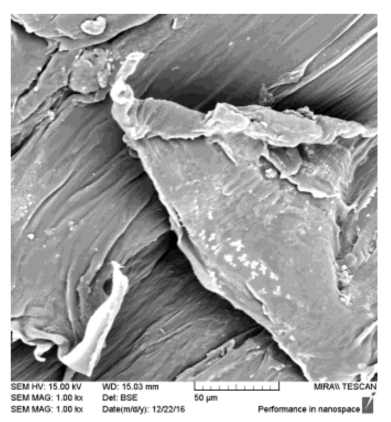

(b)

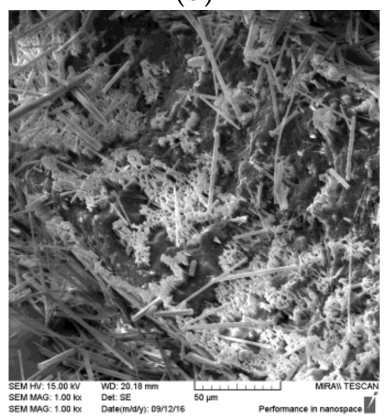

(d)

Figure 11. SEM scans of the three polymers and the final ternary blend containing $5 \%(w / w)$ caffeine: (a) PVP-VA filament cross-section; (b) PCL filament cross-section; (c) PEO filament cross-section; and (d) $25 \%$ infill 3DP tablet cross-section of F11.

\subsection{Material Considerations}

Figure 12 is a detailed schematic of an FFF extrusion head. It is best to consider the material in relation to each of the three zones of the FFF process-feed, heat, and deposition-since each zone has a specific set of challenges. The feed zone is governed by the bulk properties of the filament, which entails how successfully it copes with the driving gear mechanism. For the MakerBot ${ }^{\circledR}$ printer, the driving gear system is part of the extrusion head assembly and, therefore, feeds directly into the liquefier. These are known as direct drive extruders. On other FFF printers, the driving gear mechanism on the side of the printer at a distance removed from the extrusion head is known as a Bowden extruder. The filament is driven along feed tubing to the extrusion head. Such a system severely restricts the material that can be printed since the filament has to be sufficiently flexible and aqueous to navigate the feeding tube. Our recommendation to other researchers who are producing filaments via heat-melting extrusion is only to purchase FFF printers that have the direct driving gear feeding system since it provides much-valued leeway for printing compared to a Bowden system.

The heating zone is dominated by the material's response to being heated in a chamber. A suitable material should be able to form a consistent melting factor in the most efficient manner. Innovation in this section is related to the heating elements by providing uniform, stable heat flux and eliminating hot-spots and dead zones so that the length of the liquefier is consistently heated. For the deposition zone, the material properties are dominated by the behavior of the material to flowing, cooling, and the ability to adhere to the previous layer or print-bed. Nozzle improvement aims through innovative design to eliminate or reduce known problems in layer deposition such as die swell and to improve print resolution. It is important to note that advances in driving gear and extruder head technology is more than an annual occurrence and existing printers can be retrofitted in most instances with extrusion heads that will accommodate a wider range of materials than what was previously the case. Advances aim to reduce extrusion head weight, increase reliability and repeatability, improve print resolution, and expand the range of materials that can be printed consistently such as softer 
thermoplastics. Table 6 is a compilation of the critical material properties that must be considered when approaching the production of solid dosage forms via fused-filament fabrication.

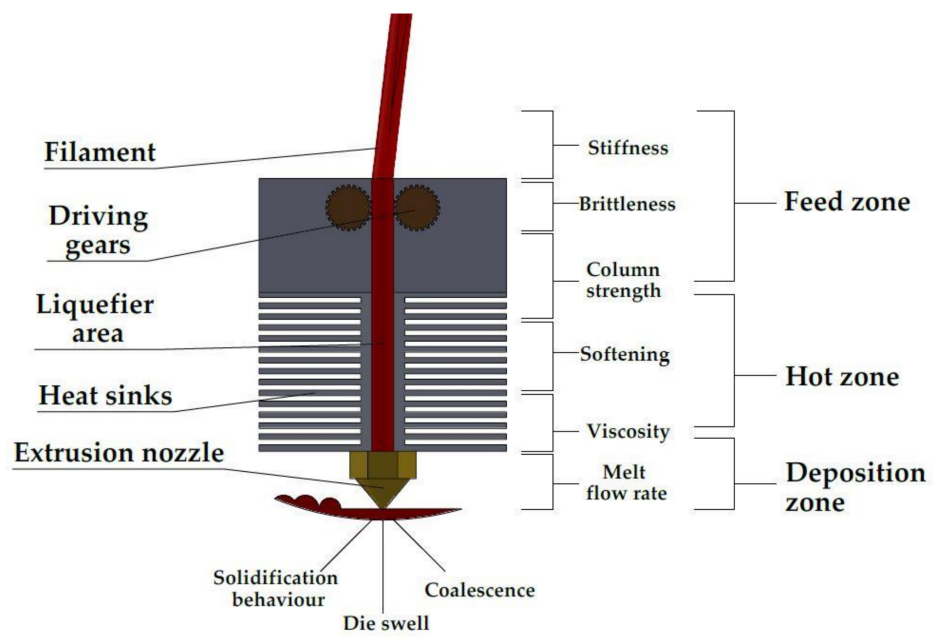

Figure 12. Detailed view of an FFF printer extrusion head with parts identified. The three distinct zones of the process are labelled and nine of the main material considerations are listed beside the sections of the extruder head in which they exert the most influence.

Table 6. Critical material properties for each zone of the FFF process and comments on each property based on experimental observation and from prior studies.

\begin{tabular}{|c|c|c|}
\hline Zone & Material Property & Comments \\
\hline \multirow{6}{*}{ Feed } & Filament stiffness & $\begin{array}{l}\text { A very stiff filament will not permit winding onto spools. Therefore, the filament remains in } \\
\text { the vertical axis and length will be limited by room height or other obstructions. Above a } \\
\text { certain stiffness, feed length will be determined by height, which can self-support weight. } \\
\text { For pre-screening, material stiffness can be measured in a number of different modes, tensile, } \\
\text { flexural, or torsion. We utilized a DMA in the single cantilever, but a universal tester (tensile, } \\
\text { flexural, and torsion) or a texture analyser can also be used [13,73]. Zhang et al. [13] allocated } \\
\text { the breaking stress as a quantification of filament stiffness as tested by using a } \\
\text { texture analyzer. }\end{array}$ \\
\hline & Filament brittleness & $\begin{array}{l}\text { Brittle filaments can snap in the driving gears and prevent feeding. } \\
\text { Brittleness }(\mathrm{B}) \text { can be calculated from strain-at-break }\left(\varepsilon_{\mathrm{b}}\right) \text { and storage modulus }\left(\mathrm{E}^{\prime}\right) \text { using the } \\
\text { Brostow-Hagg Lobland-Narkis Equation (see Equation }(2)) \text { for brittleness [37]. Primarily } \\
\text { elongation-at break }(\%) \text { is the value calculated for } \varepsilon_{\mathrm{b}} \text { and the values are obtained from tensile } \\
\text { testing if the correct test specimens are available [74]. Our modified approach was to test } \\
\text { filament lengths to obtain strain-at-break from 3-point bending directly. Others have } \\
\text { performed similar tests but solely defined the strain-at-break data as a brittleness } \\
\text { measurement [13,73]. We calculate that B should be less than } 0.0002 \% \text { Pa for materials to } \\
\text { make suitable filaments. }\end{array}$ \\
\hline & Column strength & $\begin{array}{l}\text { Since most filaments act as a piston on the melt-front in the liquefier, the ability of the } \\
\text { filament to withstand compressive force without buckling is an important variable }[68,75] \text {. } \\
\text { Venkataraman et al. [68] determined a critical ratio for ceramic-based filaments above which } \\
\text { a filament will withstand buckling. The ratio states that, if the elastic modulus of the filament } \\
\text { is greater than the apparent viscosity by } 3-5 \times 10^{5} \mathrm{~s}^{-1} \text { then the filament will maintain } \\
\text { sufficient column strength during printing. } \\
\text { Most thermoplastic materials will maintain the critical ratio [75], but it is a useful } \\
\text { pre-screening tool for untypical materials or highly-filled materials. }\end{array}$ \\
\hline & Filament softness & $\begin{array}{l}\text { Soft materials can be squeezed between driving gears, which would limite or prevent feeding. } \\
\text { Material hardness can be measured a number of ways, but the Shore durometer method is } \\
\text { the most common approach [76]. }\end{array}$ \\
\hline & Dimensional consistency & $\begin{array}{l}\text { Filament consistency will determine the feed rate to the heating end. } \\
\text { Consistency is more than just a measure of filament diameter and can include ovality, } \\
\text { pockmarks, gaps, and general deformities. } \\
\text { Visual inspection is sufficient for eliminating the majority of the irregular filament. }\end{array}$ \\
\hline & Filament diameter & $\begin{array}{l}\text { Diameter ultimately determines feed rate to the heating end. Inconsistent filament diameter } \\
\text { will result in inconsistent deposition and poor prints. } \\
\text { Extrusion flow surging is a problem that occurs due to fluctuations in the feed or transition } \\
\text { zone in the extrusion process [45]. A melt pump will eradicate the problem and produce a } \\
\text { uniform filament but at added capital cost. } \\
\text { Consistent material feeding and a correct temperature profile that permits stable melt } \\
\text { formation can eliminate most surging. Die design can reduce the phenomenon and a longer } \\
\text { land length by promoting a consistent melt output. } \\
\text { Filament diameter is best measured at the point of filament production using laser } \\
\text { micrometers or ultrasonic gauges. }\end{array}$ \\
\hline
\end{tabular}


Table 6. Cont

\begin{tabular}{|c|c|c|}
\hline Zone & Material Property & Comments \\
\hline \multirow[t]{2}{*}{ Hot } & Melt viscosity & $\begin{array}{l}\text { As material softens and begins to melt, feeding from the melt to the nozzle is dependent on } \\
\text { the back pressure formed due to the action of the driving gears forcing the } \\
\text { filament downwards. } \\
\text { High viscosity and the back pressure will be insufficient to force the melt through the nozzle } \\
\text { die. Too high a force can lead to buckling of the filament [68]. } \\
\text { Low viscosity and too much material will be pushed through the nozzle by preventing } \\
\text { proper deposition. } \\
\text { Melt viscosity is determined by a rheometer. A capillary rheometer at low shear is best suited } \\
\text { since it most closely resembles the FFF extruder setup. }\end{array}$ \\
\hline & Softening & $\begin{array}{l}\text { Filament entering past the driving gear acts as a piston on the molten polymer below and, } \\
\text { therefore, must maintain sufficient stiffness before melting to create the required back } \\
\text { pressure. If the filament softens too soon, piston action efficiency will decrease and hinder } \\
\text { melt deposition. } \\
\text { A DMA storage modulus curve is a good representation of the stiffness of the material over } \\
\text { an elevated temperature range. }\end{array}$ \\
\hline \multirow{6}{*}{ Deposition } & Melt flow rate & $\begin{array}{l}\text { Melt flow rate is related to viscosity and is temperature dependent. } \\
\text { High flow rate materials will more easily be pushed through the liquefier and nozzle. } \\
\text { Too high and melt deposition will be uncontrollable. } \\
\text { Low flow rate materials will be harder to push through the liquefier and nozzle. Too low of a } \\
\text { flow rate and melt deposition becomes unachievable. } \\
\text { The melt flow rate is determined by a melt flow indexer. } \\
\text { Wang et al. [77] have recently determined that commercial filament grades should be greater } \\
\text { than } 10 \mathrm{~g} / 10 \mathrm{~min} \text { to achieve acceptable print quality. }\end{array}$ \\
\hline & Melt feed consistency & $\begin{array}{l}\text { The homogeneous flow of material is a critical necessity for a successful 3DP part. } \\
\text { Surge feeding or starvation of material result in imperfection in the part's building process. } \\
\text { Most common signs of feed inconsistency are missing layers, layers misalignment, weak } \\
\text { infill, low dimensional accuracy, and layer splitting. } \\
\text { Feedstock material with consistent dimensions is crucial. }\end{array}$ \\
\hline & Coalescence & $\begin{array}{l}\text { Poor layer coalescence leads to inconsistencies in the structure of the printed parts, which } \\
\text { creates critical points of failure, poor performance, and geometrical discrepancies. } \\
\text { Coalescence increases with decreases in melt viscosity since there is greater polymer chain } \\
\text { mobility and intermingling between layers [78]. Therefore, poor interlayer adhesion may be } \\
\text { improved through higher printing temperatures. } \\
\text { If deposited layers fail to adhere, print quality suffers considerably. Finished parts with the } \\
\text { strong layer-to-layer union will possess higher mechanical toughness [79]. }\end{array}$ \\
\hline & Shrinkage and Warpage & $\begin{array}{l}\text { Parts with subpar adhesion to the printing bed could exhibit warping due to deposited layers } \\
\text { cooling down and contracting because of internal stresses, which results in } \\
\text { partial deformation. } \\
\text { If material fails to stick properly to the printing bed, a higher printing bed temperature might } \\
\text { be necessary. } \\
\text { The use of Kapton tape or Scotch }{ }^{\mathrm{TM}} \text { blue painters tape improves the adhesion of materials to } \\
\text { the printing bed and protects the bed from scratches. } \\
\text { Environmental conditions, such as room temperature, should be taken into consideration } \\
\text { when dealing with poor adhesion or warping since thermal gradients are the primary cause } \\
\text { of internal stress [70]. } \\
\text { Correction factors can be applied at the design stage to accommodate for known print } \\
\text { shrinkage of specific materials. These factors are prevalent for common materials and are a } \\
\text { common feature of 3D printing software. Kaveh } 2015 \text { et al. [80] describe a means for } \\
\text { determining correction factors for material through the printing of a series of cubes, } \\
\text { cylinders, and stairs. }\end{array}$ \\
\hline & Moisture content & $\begin{array}{l}\text { Trapped water will evaporate by exiting the nozzle and creating bubbles inside the extruded } \\
\text { material, which disrupts the steady deposition of layers [81]. } \\
\text { When using hygroscopic materials for long printing processes, it is important to consider the } \\
\text { storage conditions of the feedstock material used for manufacturing. Production could fail } \\
\text { due to absorption of moisture by the material. Adequate drying procedures should be } \\
\text { adopted for an improperly stored filament. }\end{array}$ \\
\hline & Die swell & $\begin{array}{l}\text { Die swell is a well-established issue in polymer extrusion. The phenomena relates to the } \\
\text { exiting diameter of the extrudate being greater than the diameter of the die and is related to } \\
\text { the viscoelastic nature of the polymer. Die swell increases with increasing polymer molecular } \\
\text { weight. It will affect the quality of the final print since it reduces the dimensional accuracy of } \\
\text { the deposited layer. } \\
\text { Die swell from the liquefier nozzle may be reduced through changes to the material } \\
\text { formulation or changes in the nozzle design. However, the short land length of FFF printer } \\
\text { nozzles may preclude the latter option. The primary means of dealing with die swell is to } \\
\text { accommodate the design by specifying the deposited layer thickness to be 1.2-1.5 times the } \\
\text { nozzle die diameter [82]. } \\
\text { Material die swell can be measured using a capillary die rheometer [83]. }\end{array}$ \\
\hline
\end{tabular}

\section{Conclusions}

Fused filament fabrication is an HME-based 3D printing process that is finding increasing utility in pharmaceutical applications. However, the ready-use of established matrix polymers is limited due to the physical restrictions imposed by the mechanics of the process. We have described in detail the main considerations to be undertaken at each of the three zones of the standard fused-filament 
fabrication printers. We have also described an HME melt-blending approach that can be readily adopted by others for the production of solid dosage forms. Melt-blending is a well-established, cost-effective, and convenient means of combining the properties of two or more polymers into a single matrix material. The final properties of the matrix material can be altered by changing the composition of the polymers. For the formulation scientist, the melt-blending framework is suitably flexible to accommodate both the requirements of the final dosage form and any physical shortcomings of the main matrix polymer under evaluation during fused-filament fabrication.

Acknowledgments: Funding for this work came from AIT President's Seed Fund and Technological Higher Education Association (Ireland).

Author Contributions: Ian Major conceived and designed the experiments. Evert Fuenmayor, Martin Forde and Andrew V. Healy performed the experiments. Evert Fuenmayor, Andrew V. Healy, Christopher McConville and Ian Major analyzed the data. Declan M. Devine and John G. Lyons contributed equipment and analysis tools. Evert Fuenmayor, Andrew V. Healy, Christopher McConville and Ian Major wrote the paper.

Conflicts of Interest: The authors declare no conflict of interest.

\section{References}

1. Norman, J.; Madurawe, R.D.; Moore, C.M.V.; Khan, M.A.; Khairuzzaman, A. A new chapter in pharmaceutical manufacturing: 3D-printed drug products. Adv. Drug Deliv. Rev. 2016. [CrossRef] [PubMed]

2. Gross, B.C.; Erkal, J.L.; Lockwood, S.Y.; Chen, C.; Spence, D.M. An evaluation of 3D printing and its potential impact on biotechnology and the chemical sciences. Anal. Chem. 2014, 86, 3240-3253. [CrossRef] [PubMed]

3. Jonathan, G.; Karim, A. 3D printing in pharmaceutics: A new tool for designing customized drug delivery systems. Int. J. Pharm. 2016, 499, 376-394. [CrossRef]

4. Yoo, J.; Thomas, J.; Bradbury; Bebb, T.J.; Iskra, J.; Surprenant, H.L.; West, T.G. Three-Dimensional Printing System and Equipment Assembly. U.S. Patent 9,517,591, 13 December 2016.

5. Tiwari, R.V.; Patil, H.; Repka, M. A Contribution of hot-melt extrusion technology to advance drug delivery in the 21st century. Expert Opin. Drug Deliv. 2016, 13, 451-464. [CrossRef] [PubMed]

6. Long, J.; Gholizadeh, H.; Lu, J.; Bunt, C.; Seyfoddin, A. Application of Fused Deposition Modelling (FDM) Method of 3D Printing in Drug Delivery. Curr. Pharm. Des. 2017, 23, 433-439. [CrossRef] [PubMed]

7. Goyanes, A.; Buanz, A.B.M.; Basit, A.W.; Gaisford, S. Fused-filament 3D printing (3DP) for fabrication of tablets. Int. J. Pharm. 2014, 476, 88-92. [CrossRef] [PubMed]

8. Tagami, T.; Fukushige, K.; Ogawa, E.; Hayashi, N.; Ozeki, T. 3D Printing Factors Important for the Fabrication of Polyvinylalcohol Filament-Based Tablets. Biol. Pharm. Bull. 2017, 40, 357-364. [CrossRef] [PubMed]

9. Goyanes, A.; Buanz, A.B.M.; Hatton, G.B.; Gaisford, S.; Basit, A.W. 3D printing of modified-release aminosalicylate (4-ASA and 5-ASA) tablets. Eur. J. Pharm. Biopharm. 2015, 89, 157-162. [CrossRef] [PubMed]

10. Chai, X.; Chai, H.; Wang, X.; Yang, J.; Li, J.; Zhao, Y.; Cai, W.; Tao, T.; Xiang, X. Fused Deposition Modeling (FDM) 3D Printed Tablets for Intragastric Floating Delivery of Domperidone. Sci. Rep. 2017, 7, 2829. [CrossRef] [PubMed]

11. Goyanes, A.; Chang, H.; Sedough, D.; Hatton, G.B.; Wang, J.; Buanz, A.; Gaisford, S.; Basit, A.W. Fabrication of controlled-release budesonide tablets via desktop (FDM) 3D printing. Int. J. Pharm. 2015, 496, 414-420. [CrossRef] [PubMed]

12. Goyanes, A.; Robles Martinez, P.; Buanz, A.; Basit, A.W.; Gaisford, S. Effect of geometry on drug release from 3D printed tablets. Int. J. Pharm. 2015, 494, 657-663. [CrossRef] [PubMed]

13. Zhang, J.; Feng, X.; Patil, H.; Tiwari, R.V.; Repka, M.A. Coupling 3D printing with hot-melt extrusion to produce controlled-release tablets. Int. J. Pharm. 2017, 519, 186-197. [CrossRef] [PubMed]

14. Beck, R.C.R.; Chaves, P.S.; Goyanez, A.; Vukosavljevic, B.; Buanz, A.; Windbergs, M.; Basit, A.W.; Gaisford, S. 3D printed tablets loaded with polymeric nanocapsules: An innovative approach to produce customized drug delivery systems. Int. J. Pharm. 2017, 528, 268-279. [CrossRef] [PubMed]

15. Okwuosa, T.C.; Pereira, B.C.; Arafat, B.; Cieszynska, M.; Isreb, A.; Alhnan, M.A. Fabricating a Shell-Core Delayed Release Tablet Using Dual FDM 3D Printing for Patient-Centred Therapy. Pharm. Res. 2016. [CrossRef] [PubMed] 
16. Okwuosa, T.C.; Stefaniak, D.; Arafat, B.; Isreb, A.; Wan, K.W.; Alhnan, M.A. A Lower Temperature FDM 3D Printing for the Manufacture of Patient-Specific Immediate Release Tablets. Pharm. Res. 2016, 33, 2704-2712. [CrossRef] [PubMed]

17. Gioumouxouzis, C.I.; Katsamenis, O.L.; Bouropoulos, N.; Fatouros, D.G. 3D printed oral solid dosage forms containing hydrochlorothiazide for controlled drug delivery. J. Drug Deliv. Sci. Technol. 2017, 40, 164-171. [CrossRef]

18. Sadia, M.; Sośnicka, A.; Arafat, B.; Isreb, A.; Ahmed, W.; Kelarakis, A.; Alhnan, M.A. Adaptation of pharmaceutical excipients to FDM 3D printing for the fabrication of patient-tailored immediate release tablets. Int. J. Pharm. 2016, 513, 659-668. [CrossRef] [PubMed]

19. Goyanes, A.; Fina, F.; Martorana, A.; Sedough, D.; Gaisford, S.; Basit, A.W. Development of modified release 3D printed tablets (printlets) with pharmaceutical excipients using additive manufacturing. Int. J. Pharm. 2017. [CrossRef] [PubMed]

20. Goyanes, A.; Kobayashi, M.; Martínez-Pacheco, R.; Gaisford, S.; Basit, A.W. Fused-filament 3D printing of drug products: Microstructure analysis and drug release characteristics of PVA-based caplets. Int. J. Pharm. 2016, 514, 290-295. [CrossRef] [PubMed]

21. Goyanes, A.; Wang, J.; Buanz, A.; Martínez-Pacheco, R.; Telford, R.; Gaisford, S.; Basit, A.W. 3D Printing of Medicines: Engineering Novel Oral Devices with Unique Design and Drug Release Characteristics. Mol. Pharm. 2015, 12, 4077-4084. [CrossRef] [PubMed]

22. Holländer, J.; Genina, N.; Jukarainen, H.; Khajeheian, M.; Rosling, A.; Mäkilä, E.; Sandler, N. Three-Dimensional Printed PCL-Based Implantable Prototypes of Medical Devices for Controlled Drug Delivery. J. Pharm. Sci. 2016, 105, 2665-2676. [CrossRef] [PubMed]

23. Genina, N.; Holländer, J.; Jukarainen, H.; Mäkilä, E.; Salonen, J.; Sandler, N. Ethylene vinyl acetate (EVA) as a new drug carrier for 3D printed medical drug delivery devices. Eur. J. Pharm. Sci. 2016, 90, 53-63. [CrossRef] [PubMed]

24. Kempin, W.; Franz, C.; Koster, L.; Schneider, F.; Bogdahn, M.; Weitschies, W.; Seidlitz, A. Assessment of different polymers and drug loads for fused deposition modeling of drug loaded implants. Eur. J. Pharm. Biopharm. 2017, 115, 84-93. [CrossRef] [PubMed]

25. Weisman, J.A.; Nicholson, J.C.; Tappa, K.; Jammalamadaka, U.; Wilson, C.G.; Mills, D.K. Antibiotic and chemotherapeutic enhanced three-dimensional printer filaments and constructs for biomedical applications. Int. J. Nanomed. 2015, 357. [CrossRef]

26. Alhijjaj, M.; Belton, P.; Qi, S. An investigation into the use of polymer blends to improve the printability of and regulate drug release from pharmaceutical solid dispersions prepared via fused deposition modeling (FDM) 3D printing. Eur. J. Pharm. Biopharm. 2016, 108, 111-125. [CrossRef] [PubMed]

27. Melocchi, A.; Parietti, F.; Maroni, A.; Foppoli, A.; Gazzaniga, A.; Zema, L. Hot-melt extruded filaments based on pharmaceutical grade polymers for 3D printing by fused deposition modeling. Int. J. Pharm. 2016, 509, 255-263. [CrossRef] [PubMed]

28. Goyanes, A.; Det-Amornrat, U.; Wang, J.; Basit, A.W.; Gaisford, S. 3D scanning and 3D printing as innovative technologies for fabricating personalized topical drug delivery systems. J. Control. Release 2016, 234, 41-48. [CrossRef] [PubMed]

29. Debotton, N.; Dahan, A. Applications of Polymers as Pharmaceutical Excipients in Solid Oral Dosage Forms. Med. Res. Rev. 2017, 37, 52-97. [CrossRef] [PubMed]

30. Major, I.; Fuenmayor, E.; McConville, C. The Production of Solid Dosage Forms from Non-Degradable Polymers. Curr. Pharm. Des. 2016, 22, 2738-2760. [CrossRef] [PubMed]

31. Elder, D.P.; Kuentz, M.; Holm, R. Pharmaceutical excipients-quality, Regulatory and biopharmaceutical considerations. Eur. J. Pharm. Sci. 2016, 87, 88-99. [CrossRef] [PubMed]

32. Evans, J. 3D printing makes material advances: Companies are stepping up their efforts to expand the limited palette of resins suitable for additive manufacturing. Plast. Eng. 2016, 72, 32-34.

33. Gilmer, E.L.; Miller, D.; Chatham, C.A.; Zawaski, C.; Fallon, J.J.; Pekkanen, A.; Long, T.E.; Williams, C.B.; Bortner, M.J. Model analysis of feedstock behavior in fused filament fabrication: Enabling rapid materials screening. Polymer 2017. [CrossRef]

34. Bühler, V. Kollidon, V. Kollidon ${ }^{\circledR}$ Polyvinylpyrrolidone excipients. Pharm. Ind. 2008, 9, 207-220. 
35. Forde, M.; Lyons, J.G.; Devine, D.M.; McConville, C.; Major, I. Dual-layer Vaginal Tablet for the Treatment of Cervical Cancer. In Proceedings of the Irish Association for Cancer Research Annual Meeting 2017, Kilkenny, Ireland, 23-24 February 2017.

36. McConville, C.; Major, I.; Devlin, B.; Brimer, A. Development of a multi-layered vaginal tablet containing dapivirine, levonorgestrel and acyclovir for use as a multipurpose prevention technology. Eur. J. Pharm. Biopharm. 2016, 104, 171-179. [CrossRef] [PubMed]

37. Brostow, W.; Hagg Lobland, H.E.; Narkis, M. Sliding wear, viscoelasticity, and brittleness of polymers. J. Mater. Res. 2006, 21, 2422-2428. [CrossRef]

38. Lyons, J.G.; Blackie, P.; Higginbotham, C.L. The significance of variation in extrusion speeds and temperatures on a PEO/PCL blend based matrix for oral drug delivery. Int. J. Pharm. 2008, 351, 201-208. [CrossRef] [PubMed]

39. Verreck, G.; Decorte, A.; Li, H.; Tomasko, D.; Arien, A.; Peeters, J.; Rombaut, P.; Van den Mooter, G.; Brewster, M.E. The effect of pressurized carbon dioxide as a plasticizer and foaming agent on the hot melt extrusion process and extrudate properties of pharmaceutical polymers. J. Supercrit. Fluids 2006, 38, 383-391. [CrossRef]

40. Bley, H.; Fussnegger, B.; Bodmeier, R. Characterization and stability of solid dispersions based on PEG/polymer blends. Int. J. Pharm. 2010, 390, 165-173. [CrossRef] [PubMed]

41. Thiry, J.; Lebrun, P.; Vinassa, C.; Adam, M.; Netchacovitch, L.; Ziemons, E.; Hubert, P.; Krier, F.; Evrard, B. Continuous production of itraconazole-based solid dispersions by hot melt extrusion: Preformulation, optimization and design space determination. Int. J. Pharm. 2016, 515, 114-124. [CrossRef] [PubMed]

42. Song, Y.; Wang, L.; Yang, P.; Wenslow, R.M.; Tan, B.; Zhang, H.; Deng, Z. Physicochemical Characterization of Felodipine-Kollidon VA64 Amorphous Solid Dispersions Prepared by Hot-Melt Extrusion. J. Pharm. Sci. 2013, 102, 1915-1923. [CrossRef] [PubMed]

43. Lehmkemper, K.; Kyeremateng, S.O.; Degenhardt, M.; Sadowski, G. Influence of Low-Molecular-Weight Excipients on the Phase Behavior of PVPVA64 Amorphous Solid Dispersions. Pharm. Res. 2018, 35. [CrossRef] [PubMed]

44. Liu, J.; Cao, F.; Zhang, C.; Ping, Q. Use of polymer combinations in the preparation of solid dispersions of a thermally unstable drug by hot-melt extrusion. Acta Pharm. Sin. B 2013, 3, 263-272. [CrossRef]

45. Li, Y.; Lu, M.; Wu, C. PVP VA64 as a novel release-modifier for sustained-release mini-matrices prepared via hot melt extrusion. Drug Deliv. Transl. Res. 2017. [CrossRef] [PubMed]

46. Kim, G.M.; Le, K.H.T.; Giannitelli, S.M.; Lee, Y.J.; Rainer, A.; Trombetta, M. Electrospinning of PCL/PVP blends for tissue engineering scaffolds. J. Mater. Sci. Mater. Med. 2013, 24, 1425-1442. [CrossRef] [PubMed]

47. Lee, Y.J.; Elosegui-Artola, A.; Le, K.H.T.; Kim, G.M. Morphological cues for regulation of cell adhesion and motility with tailored electrospun scaffolds of pcl and pcl/pvp blends. Cell. Mol. Bioeng. 2013, 6, 482-492. [CrossRef]

48. Shonaike, G.O.; Simon, G.P. Polymer Blends and Alloys; Marcel Dekker: New York, NY, USA, 1999; ISBN 0824719808.

49. Mc Conville, C.; Major, I.; Friend, D.R.; Clark, M.R.; Woolfson, A.D.; Malcolm, R.K. Development of polylactide and polyethylene vinyl acetate blends for the manufacture of vaginal rings. J. Biomed. Mater. Res. Part B Appl. Biomater. 2012, 100B, 891-895. [CrossRef] [PubMed]

50. Barmpalexis, P.; Koutsidis, I.; Karavas, E.; Louka, D.; Papadimitriou, S.A.; Bikiaris, D.N. Development of $\mathrm{PVP} / \mathrm{PEG}$ mixtures as appropriate carriers for the preparation of drug solid dispersions by melt mixing technique and optimization of dissolution using artificial neural networks. Eur. J. Pharm. Biopharm. 2013, 85, 1219-1231. [CrossRef] [PubMed]

51. Janssens, S.; de Armas, H.N.; D'Autry, W.; Van Schepdael, A.; Van den Mooter, G. Characterization of ternary solid dispersions of Itraconazole in polyethylene glycol 6000/polyvidone-vinylacetate 64 blends. Eur. J. Pharm. Biopharm. 2008, 69, 1114-1120. [CrossRef] [PubMed]

52. Rocha, C.R.; Torrado Perez, A.R.; Roberson, D.A.; Shemelya, C.M.; MacDonald, E.; Wicker, R.B. Novel ABS-based binary and ternary polymer blends for material extrusion 3D printing. J. Mater. Res. 2014, 29, 1859-1866. [CrossRef]

53. Roberson, D.; Shemelya, C.M.; MacDonald, E.; Wicker, R. Expanding the applicability of FDM-type technologies through materials development. Rapid Prototyp. J. 2015, 21, 137-143. [CrossRef] 
54. Siqueiros, J.G.; Schnittker, K.; Roberson, D.A. ABS-maleated SEBS blend as a 3D printable material. Virtual Phys. Prototyp. 2016, 11, 123-131. [CrossRef]

55. Decker, N.; Yee, A. Assessing the use of binary blends of acrylonitrile butadiene styrene and post-consumer high density polyethylene in fused filament fabrication. Int. J. Addit. Subtrac. Mater. Manuf. 2017, 1, 161-171. [CrossRef]

56. Cicala, G.; Ognibene, G.; Portuesi, S.; Blanco, I.; Rapisarda, M.; Pergolizzi, E.; Recca, G. Comparison of Ultem 9085 used in fused deposition modelling (FDM) with polytherimide blends. Materials 2018, 11, 285. [CrossRef] [PubMed]

57. Zhu, J.; Hu, Y.; Tang, Y.; Wang, B. Effects of styrene-acrylonitrile contents on the properties of ABS/SAN blends for fused deposition modeling. J. Appl. Polym. Sci. 2017, 134. [CrossRef]

58. Kosorn, W.; Sakulsumbat, M.; Uppanan, P.; Kaewkong, P.; Chantaweroad, S.; Jitsaard, J.; Sitthiseripratip, K.; Janvikul, W. PCL/PHBV blended three dimensional scaffolds fabricated by fused deposition modeling and responses of chondrocytes to the scaffolds. J. Biomed. Mater. Res. Part B Appl. Biomater. 2017, 105, 1141-1150. [CrossRef] [PubMed]

59. Hutmacher, D.W.; Schantz, T.; Zein, I.; Ng, K.W.; Teoh, S.H.; Tan, K.C. Mechanical properties and cell cultural response of polycaprolactone scaffolds designed and fabricated via fused deposition modeling. J. Biomed. Mater. Res. 2001, 55, 203-216. [CrossRef]

60. Woodruff, M.A.; Hutmacher, D.W. The return of a forgotten polymer-Polycaprolactone in the 21st century. Prog. Polym. Sci. 2010, 35, 1217-1256. [CrossRef]

61. Solanki, N.G.; Tahsin, M.; Shah, A.V.; Serajuddin, A.T.M. Formulation of 3D Printed Tablet for Rapid Drug Release by Fused Deposition Modeling: Screening Polymers for Drug Release, Drug-Polymer Miscibility and Printability. J. Pharm. Sci. 2018, 107, 390-401. [CrossRef] [PubMed]

62. Maeyaert, G.R.K. Bulk Compounding of PCL-PEO Blends for 3D Plotting of Scaffolds for Cardiovascular Tissue Engineering. J. Mater. Sci. Eng. 2013, 3, 3-6. [CrossRef]

63. Lin, W.; Flanagan, D.R.; Linhardt, R.J. A novel fabrication of poly( $\varepsilon$-caprolactone) microspheres from blends of poly( $\varepsilon$-caprolactone) and poly(ethylene glycol) s. Polymer 1999, 40, 1731-1735. [CrossRef]

64. Wu, D.C.; Loh, X.J.; Wu, Y.L.; Lay, C.L.; Liu, Y. "Living” controlled in situ gelling systems: Thiol-disulfide exchange method toward tailor-made biodegradable hydrogels. J. Am. Chem. Soc. 2010, 132, 15140-15143. [CrossRef] [PubMed]

65. Liu, K.L.; Widjaja, E.; Huang, Y.; Ng, X.W.; Loo, S.C.J.; Boey, F.Y.C.; Venkatraman, S.S. A New Insight for an Old System: Protein-PEG Colocalization in Relation to Protein Release from PCL/PEG Blends. Mol. Pharm. 2011, 8, 2173-2182. [CrossRef] [PubMed]

66. Capone, C.; Di Landro, L.; Inzoli, F.; Penco, M.; Sartore, L. Thermal and mechanical degradation during polymer extrusion processing. Polym. Eng. Sci. 2007, 47, 1813-1819. [CrossRef]

67. Miller, E.; Rothstein, J.P. Control of the sharkskin instability in the extrusion of polymer melts using induced temperature gradients. Rheol. Acta 2004, 44, 160-173. [CrossRef]

68. Venkataraman, N.; Rangarajan, S.; Matthewson, M.J.; Harper, B.; Safari, A.; Danforth, S.C.; Wu, G.; Langrana, N.; Guceri, S.; Yardimci, A. Feedstock material property-process relationships in fused deposition of ceramics (FDC). Rapid Prototyp. J. 2000, 6, 244-253. [CrossRef]

69. Fischer, J.M. Handbook of Molded Part Shrinkage and Warpage; William Andrew: Amsterdam, The Netherlands, 2013; ISBN 1455730572.

70. Turner, B.N.; Gold, S.A. A review of melt extrusion additive manufacturing processes: II. Materials, dimensional accuracy, and surface roughness. Rapid Prototyp. J. 2015, 21, 250-261. [CrossRef]

71. Barlow, J.W.; Paul, D.R. Polymer blends and alloys-A review of selected considerations. Polym. Eng. Sci. 1981, 21, 985-996. [CrossRef]

72. Mofokeng, J.P.; Luyt, A.S. Dynamic mechanical properties of PLA/PHBV, PLA/PCL, PHBV/PCL blends and their nanocomposites with $\mathrm{TiO}_{2}$ as nanofiller. Thermochim. Acta 2015, 613, 41-53. [CrossRef]

73. Verstraete, G.; Samaro, A.; Grymonpré, W.; Vanhoorne, V.; Van Snick, B.; Boone, M.N.; Hellemans, T.; Van Hoorebeke, L.; Remon, J.P.; Vervaet, C. 3D printing of high drug loaded dosage forms using thermoplastic polyurethanes. Int. J. Pharm. 2018, 536, 318-325. [CrossRef] [PubMed]

74. ASTM International. ASTM D638-14 Standard Test Method for Tensile Properties of Plastics; ASTM International: West Conshohocken, PA, USA, 2014. 
75. Espalin, D.; Alberto Ramirez, J.; Medina, F.; Johnson, W.M.; Rowell, M.; Deason, B.; Eubanks, M.; Turner, B.N.; Strong, R.; Gold, S.A. Rapid Prototyping Journal A review of melt extrusion additive manufacturing processes: I. Process design and modeling. Rapid Prototyp. J. 2014, 20, 192-204. [CrossRef]

76. ASTM International. ASTM D2240-15e1 Standard Test Method for Rubber Property-Durometer Hardness; ASTM International: West Conshohocken, PA, USA, 2015.

77. Wang, S.; Capoen, L.; D’hooge, D.R.; Cardon, L. Can the melt flow index be used to predict the success of fused deposition modelling of commercial poly(lactic acid) filaments into 3D printed materials? Plast. Rubber Compos. 2018, 47, 9-16. [CrossRef]

78. Shahriar, B.B.; France, C.; Valerie, N.; Arthur, C.; Christian, G. Toward improvement of the properties of parts manufactured by FFF (fused filament fabrication) through understanding the influence of temperature and rheological behaviour on the coalescence phenomenon. AIP Conf. Proc. 2017, 1896. [CrossRef]

79. Ahn, S.; Montero, M.; Odell, D.; Roundy, S.; Wright, P.K. Anisotropic material properties of fused deposition modeling ABS. Rapid Prototyp. J. 2002, 8, 248-257. [CrossRef]

80. Kaveh, M.; Badrossamay, M.; Foroozmehr, E.; Hemasian Etefagh, A. Optimization of the printing parameters affecting dimensional accuracy and internal cavity for HIPS material used in fused deposition modeling processes. J. Mater. Process. Technol. 2015, 226, 280-286. [CrossRef]

81. Halidi, S.N.A.M.; Abdullah, J. Moisture effects on the ABS used for Fused Deposition Modeling rapid prototyping machine. In Proceedings of the Humanities, Science and Engineering Research (SHUSER), Kuala Lumpur, Malaysia, 24-27 June 2012. [CrossRef]

82. Agarwala, M.K.; Jamalabad, V.R.; Langrana, N.A.; Safari, A.; Whalen, P.J.; Danforth, S.C. Structural quality of parts processed by fused deposition. Rapid Prototyp. J. 1996, 2, 4-19. [CrossRef]

83. Wang, K. Die Swell of Complex Polymeric Systems. In Viscoelasticity_From Theory to Biological Applications; InTech: Houston, TX, USA, 2012.

(C) 2018 by the authors. Licensee MDPI, Basel, Switzerland. This article is an open access article distributed under the terms and conditions of the Creative Commons Attribution (CC BY) license (http://creativecommons.org/licenses/by/4.0/). 